\title{
Cyclone generation Algorithm including a THERmodynamic module for Integrated National damage Assessment (CATHERINA 1.0) compatible with CMIP climate data
}

\author{
Théo Le Guenedal ${ }^{1}$, Philippe Drobinski ${ }^{2}$, and Peter Tankov ${ }^{1}$ \\ ${ }^{1}$ CREST, ENSAE, Institut Polytechnique de Paris, Palaiseau, France \\ ${ }^{2}$ LMD-IPSL, Ecole Polytechnique, Institut Polytechnique de Paris, ENS, PSL Research University, Sorbonne Université, \\ CNRS, Palaiseau, France
}

Correspondence: Theo Le Guenedal (theo.le-guenedal@ensae.fr)

\begin{abstract}
Tropical cyclones are responsible for a large share of global damage resulting from natural disasters and estimating cyclone-related damage at a national level is a challenge attracting growing interest in the context of climate change. The global climate models, whose outputs are available from the Coupled Model Intercomparison Project (CMIP), do not resolve tropical cyclones. The Cyclone generation Algorithm including a THERmodynamic module for Integrated National damage

5 Assessment (CATHERINA) presented in this paper, couples statistical and thermodynamic relationships to generate synthetic tracks sensitive to local climate conditions and estimates the damage induced by tropical cyclones at a national level. The framework is designed to be compatible with CMIP models data offering a simple solution to resolve tropical cyclones in climate projections. We illustrate it by producing damage projections in Representative Concentration Pathways (RCP) at the global level and for individual countries. The algorithm contains a module to correct biases in climate models based on the distributions of the climate variables in the reanalyses.
\end{abstract}

\section{Introduction}

Climate-related physical risks pose a growing threat to humanity, and the design and implementation of adequate adaptation and mitigation measures require assessing future physical risks at a national and global scale. One important source of information about the future climate are the projections of the global climate models, however the spatial resolution of these global models is unfortunately still not sufficient to fully resolve extreme events, particularly tropical cyclones. On the other side of the spectrum, Integrated Assessment Models (IAM) directly assess the impact of climate on economic activity. Most of these models embed a physical damage module, usually limited to a very generic damage function. Tools to assess the impact of tropical cyclones on the economy under future climate are thus lacking in the literature. The objective of this paper is to fill this gap: we build synthetic cyclones based on the climate data produced by the global climate models, and evaluate the economic damage of these synthetic cyclones under various assumptions.

The physics of tropical cyclones has been intensively studied in the literature. The thermodynamic cyclone theory builds upon the seminal contributions by Emanuel (1988) followed by Holland (1997) and Emanuel (1999). Concerning the impact of 
climate change, it is well known that the presence of greenhouse gases in the atmosphere increases the radiative forcing, which leads to a progressive warming of the atmosphere (Butchart et al., 2000), and the rise of sea surface temperatures (Solomon et al., 2007; Pachauri et al., 2014). This phenomenon increases the amount of energy available for cyclones to grow in intensity (Emanuel, 1991) and this growth is already measurable (Emanuel, 2005). Risk assessments have been developed based on hurricane potential intensity maps to assess the damage in the US and worldwide (Emanuel et al., 2008; Emanuel, 2011; Mendelsohn et al., 2012).

Models relying on statistical relationships (James and Mason, 2005; DeMaria and Kaplan, 1994; Kaplan and DeMaria, 1995) are available in the literature to produce synthetic cyclones with properties closely resembling those of observed cyclones. Recently, Bloemendaal et al. (2020) developed a modeling framework to simulate realistic synthetic tropical cyclone tracks: the Synthetic Tropical cyclOnes geneRation Model (STORM). However, we find that the effect of climate change on the maximum potentials in the different scenarios can only be modeled by a better description of the underlying thermodynamic phenomenon, well described by Emanuel (1988); Holland (1997) or Emanuel (1999). We therefore develop an alternative to STORM by adding a thermodynamic module in the perspective of producing cyclones in different climate scenarios. In particular we retrieve two additional variables (relative humidity and tropopause temperature) from climate models to better describe the intensification process.

On the damage modeling side, Bresch (2017); Lüthi (2019); Aznar Siguan and Bresch (2019) set up a platform for physical risk estimation (CLIMADA), coupled with a database of estimated values of local assets (Eberenz et al., 2019, 2020b). The asset resolution (30 arc-sec) and geo-spatial description of extreme events is particularly advanced. We propose a simplification of this work that applies in the context of national level assessment. The CLIMADA framework focuses on damage modeling based on simplified climate projections, and does not make use of the climate data produced by atmosphere-ocean general circulation models (AOGCM). Coupling STORM methodology with our original thermodynamic module fitted on four climate variables and CLIMADA, our approach provides a better long-term tail risk assessment at a national level, and therefore a better measure of the adaptation investments needed to mitigate this risk.

This paper makes three contributions. First, we provide an algorithm to generate synthetic cyclones from climate data inspired by Bloemendaal et al. (2020) fitted on four physical variables extracted from ERA-5 reanalysis and including a thermodynamic module to better describe cyclone physics. Second, we ensure that this algorithm is compatible with CMIP models, expose the biases in CMIP5 datasets and propose a correction module based on Vrac et al. (2012). Third, we bridge the gap between climate data and damage modeling by using the physical asset values from Eberenz et al. (2020b) and computing the damage along cyclone tracks using the regional specific damage functions designed in the CLIMADA project. Combining open data sources and methodologies allows us to propose a complete bottom-up integrated physical risks assessment model for tropical cyclones presented in Figure 1: the Cyclone generation Algorithm including a THERmodynamic module for Integrated National damage Assessment (CATHERINA).

The process is the following. The cyclones are initiated with spatial and seasonal distribution estimated on the IBTrACS database similarly to Bloemendaal et al. (2020). Their movement is described with a simple auto regressive stochastic process (James and Mason, 2005; Bloemendaal et al., 2020). Along the simulated cyclone tracks, we retrieve climate variables 


\begin{tabular}{|c|c|c|}
\hline $\begin{array}{c}\text { Bias Control } \\
\text { Cumulative distribution- } \\
\text { tranform }(\text { CDF-t) } \\
F_{r, f}(x)=F_{r, h}\left(F_{m, h}^{-1}\left(F_{m, f}(x)\right)\right)\end{array}$ & $\longrightarrow$ & \multicolumn{2}{c|}{ Climate Data } \\
\cline { 2 - 3 } & $\begin{array}{c}\text { Climate data } \\
\text { Reanalysis ERA5 } \\
\text { CMIP5 Evaluation (histo.) }\end{array}$ & IBTrACs (Cyclones tracks) \\
\hline
\end{tabular}

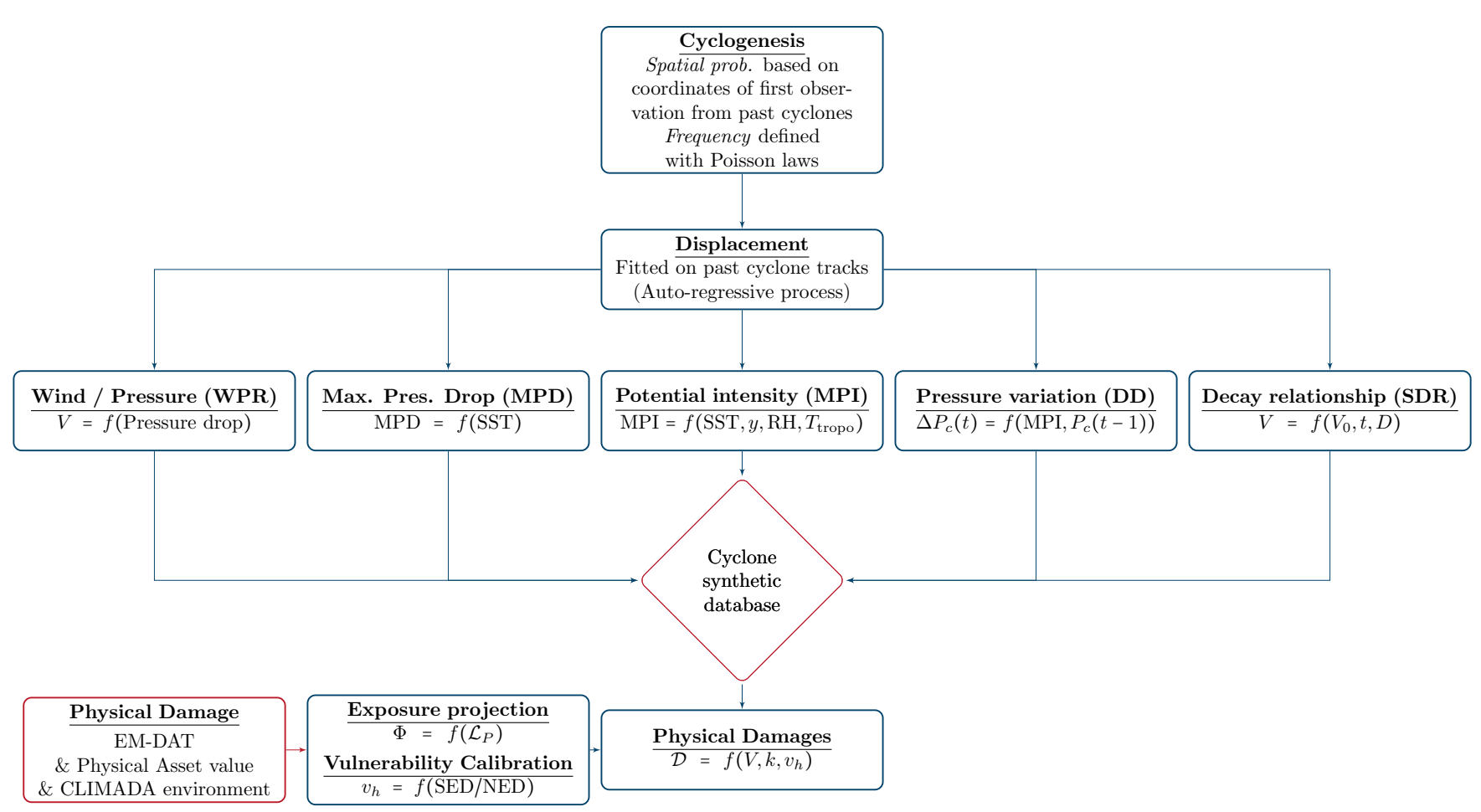

Figure 1. Cyclone generation Algorithm including a THERmodynamic module for Integrated National damage Assessment (CATHERINA) Framework

from climate models allowing to define locally the maximum potential intensity based on the simplified expression in Holland (1997). Some controls such as the maximum pressure drop observed for the corresponding temperature and the decay relationship for cyclones evolving over land are also fitted for each basin and applied in the synthetic tracks generation algorithm. Extracting the climate variables from different models allow us to correct the biases and evaluate model uncertainty. Then, we use the physical asset values (Eberenz et al., 2020b) and regional damage functions from the CLIMADA module to evaluate the cyclone-related damage at a national level. This step requires to extract the local physical asset values and aggregate them on tiles of length defined proportionally to the average radius to maximum wind $(\sim 50 \mathrm{~km})$ along the cyclone path. Summing the losses along tracks for each year and for each country allows us to establish a national assessment of the damage generated by tropical cyclones.

The paper is organized as follows. Section 2 describes the datasets used to fit the model on ERA-5 and to generate synthetic cyclones based on both ERA-5 and CMIP5 models datasets. Section 3 describes the statistical calibration process and the details of the thermodynamic instrumental variables. Section 4 recalls the calibration methods implemented in the CLIMADA 
environment to fit the regional damage functions, defines the parameters of these functions using Eberenz et al. (2020a) and applies them along the synthetic tracks produced to study the distribution of national annual damages. Section 5 explores the properties of the produced synthetic tracks, with ERA-5 and 7 CMIP models, assesses climate uncertainty and introduces the bias correction module in the context of changing climate conditions. To close this section, we present the global and regional projections of cyclone damage between 2070 and 2100 obtained with CATHERINA.

\section{Input data}

In the CATHERINA framework, we fit the properties of historical cyclones (IBTrACS database) on past climate reanalyses (ERA-5) in the perspective of describing future cyclones based on global climate models outputs (CMIP), having a lower spatial and temporal resolution. This perspective constrains us to use monthly data.

\subsection{Climate model data (CMIP)}

CATHERINA aims at generating cyclones tracks with properties drawn from climate models to enable national damage assessments, bridging the gap between AOCGM outputs and damage assessments. To reduce the bias in the variables produced by climate models ${ }^{1}$ and evaluate the performance of CATHERINA on past data by comparing the simulated cyclone damages to the realized ones we use historical simulations (as opposed to future climate projections) from the Coupled Model Intercomparison project (Phase 5) models (Taylor et al., 2012). We use the historical climate simulations at the monthly frequency for the relative humidity (RH) at two meters, sea surface temperature (SST), sea level pressure (MSLP) and tropauspose temperature $\left(T_{\text {tropo }}\right)$ (at pressure level of $50 \mathrm{hPa}$ ) from Copernicus climate data store ${ }^{2}$. CMIP5 data are used in the 5th assessment report of the Intergovernmental Panel on Climate Change (IPCC). The latest synthesis Report in progress in 2021 is IPCC $\mathrm{AR6}^{3}$, which uses CMIP6 datasets but in the present paper, we use CMIP5 data because of broader availability of climate variables.

We use models from the following climate centers: NASA, Goddard Institute for Space Studies (GISS-E2-H, USA), Institut Pierre Simon Laplace (IPSL-CM5A-NR, France), Bureau of Meteorology - Commonwealth Scientific and Industrial Research Organisation (ACCESS1-0, BoM-CSIRO, Australia), Beijin Climate Center (bcc-csm1-1-m, China), Institute of Numerical Mathematics (inmcm4, Russia), Norwegian Climate Centre (NorESM1-ME, Norway), Canadian Centre for Climate Modelling and Analysis (CanESM2, Canada). The spatial resolution goes from $0.75^{\circ}$ to $2.5^{\circ}$ depending on the model (See Table 1). Each climate model produces a potentially biased estimate of multiple climate variables at the spatial resolution given in Table 1 and on a monthly basis.

\footnotetext{
${ }^{1}$ In particular, we need the climate variables produced by climate models on a time period covered by reanalysis (cf. section 2.2 ) to define the bias correction functions (cf. section 5.1).

${ }^{2}$ Climate data is available on the Copernicus Climate data store: https://cds.climate.copernicus.eu/.

${ }^{3}$ https://www.ipcc.ch/assessment-report/ar6/.
} 
Table 1. Climate data resolution

\begin{tabular}{|l|r|}
\hline & Resolution $(\mathrm{x}, \mathrm{y})$ in degrees \\
\hline ERA-5 & $0.25 \times 0.25$ \\
ACCESS1-0 (BoM-CSIRO, & $1.875 \times 0.9331648$ \\
Australia) & $1.40625 \times 0.9364358$ \\
CanESM2 (CCCMA, Canada) & $2.5 \times 2$ \\
GISS-E2-H (NASA, USA) & $1 \times 1$ \\
NorESM1-ME (NCC, Nor- & $1 \times 0.7402597$ \\
way) & $1 \times 1$ \\
bcc-csm1-1-m (BCC, China) & \\
IPSL-CM5A-MR (IPSL, & $2 \times 1.5$ \\
France) & \\
INMCM4 (INM, Russia) & \\
\hline
\end{tabular}

To reduce the influence of these biases, we use a large number of models and consider the distribution of results provided by all the models. Then we correct, variable by variable, and for each basin, and each model, the biases with respect to the reanalysis along the same tracks.

\subsection{ERA-5 Reanalysis}

Climate reanalyses describe the historical climate conditions, obtained by assimilating all available observations into the models. They provide numerical estimates of atmospheric parameters (e.g. air temperature, pressure and wind) at different altitudes / pressure levels, and surface parameters (such as rainfall, soil moisture content, ocean-wave height and sea-surface temperature) on a single level. We use reanalyses to calibrate the cyclone generation algorithm based on the most realistic available estimates of climate variables.

We use ERA-5 reanalysis from the European Centre for Medium-Range Weather Forecasts (ECMWF) to fit CATHERINA model ${ }^{4}$. This dataset covers the Earth on a $30 \mathrm{~km}$ grid $\left(\sim 0.25^{\circ}\right)$ and resolves the atmosphere using 137 levels from the surface up to a height of $80 \mathrm{~km}$. In this paper, to ensure compatibility with CMIP5 models, we extract mean sea level pressure (MSLP), sea surface temperature (SST), sea level relative humidity $(\mathrm{RH})$, and tropopause temperature $\left(T_{\text {tropo }}\right)$ at the monthly frequency. Because reanalysis resolves past tropical cyclones, the historical mean sea level pressure values in ERA-5 are influenced by their presence. Consequently, we retrieve the mean sea level pressure $500 \mathrm{~km}\left(\sim 5^{\circ}\right.$ longitude $)$ away from the storm center to extract a value for $P_{e n v}$, that is meant to represent the pressure - at a given latitude and season - in normal environmental conditions.

\footnotetext{
${ }^{4}$ Climate data is available on the Copernicus Climate data store: https://cds.climate.copernicus.eu/.
} 


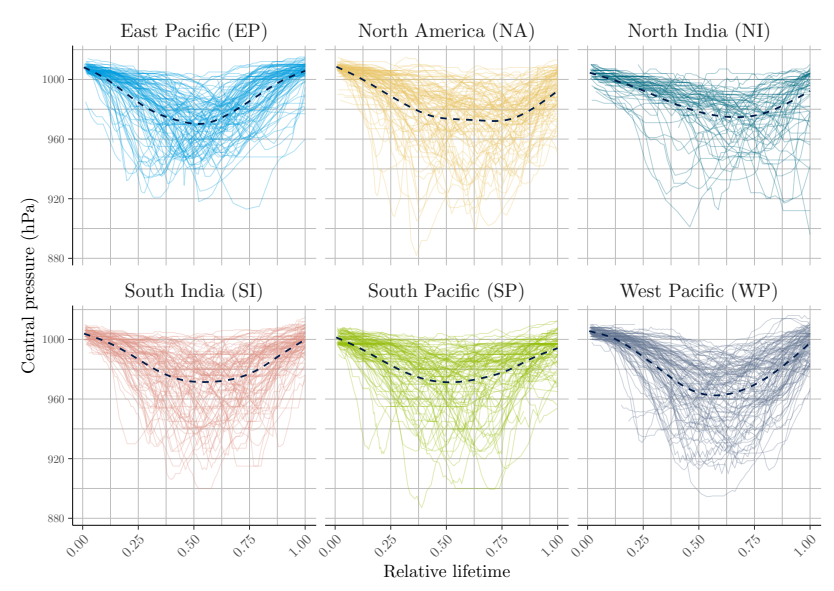

Figure 2. Normalized evolution of the central pressure (in hPa) during cyclone life of a sample of 100 storms for each basin. The dotted line represents the average pressure evolution. The central pressure values are retrieved from IBTrACS.

\subsection{Historical cyclone tracks (IBTrACS)}

We use the International Best Track Archive for Climate Stewardship (IBTrACS) database (Knapp et al., 2010) ${ }^{5}$. This database provides information on past cyclone tracks at 3-hour frequency. We remove the events classified as disturbance or extra tropical, and do not consider the South Atlantic basin ${ }^{6}$. Climate reanalysis availability requires to focus on cyclones since 1980, which reduces the database to 4411 cyclones. In the context of an integrated damage assessment, to focus on the events that have a potentially substantial impact on assets, we select only tropical cyclones with maximum wind speed exceeding $35 \mathrm{~m} . \mathrm{s}^{-1}$ obtaining 2245 cyclones. In Figure 2, we plot the central pressure along cyclone life. This graph suggests that the cyclone phases are fully represented in the database i.e. from the genesis to dissipation. The trajectories of central pressure in the North Indian basin appear more erratic, which means that we can expect to obtain less significant relationships in this basin. Specific examples of the evolution of central pressure and wind are given in Figure 3 for some famous named cyclones in the North Atlantic basin. We extract the maximum wind speed, cyclone eye pressure and coordinate variations of the eye from this database.

\subsection{Physical asset exposure and damage}

Eberenz et al. (2019) present a methodology to downscale physical asset values on a high-resolution grid using a combination of nightlight intensity, population data, and global country indicators and make their dataset fully available (Eberenz et al., 2020b). These estimates of physical asset value are based on the light intensity $L_{i}-$ from Nighttime lights of the Black Marble 2016 annual composite of the VIIRS day-night band (DNB) (Román et al., 2018) in 2016 at the 15 arc-second resolution - and

\footnotetext{
${ }^{5}$ See http://ibtracs.unca.edu/ for a browser of the data and https://www.ncdc.noaa.gov/ibtracs/index.php?name=ib- $\mathrm{v} 4$-access for the full dataset.

${ }^{6}$ See Figure A1 and A2 on page 31 for more information.
} 


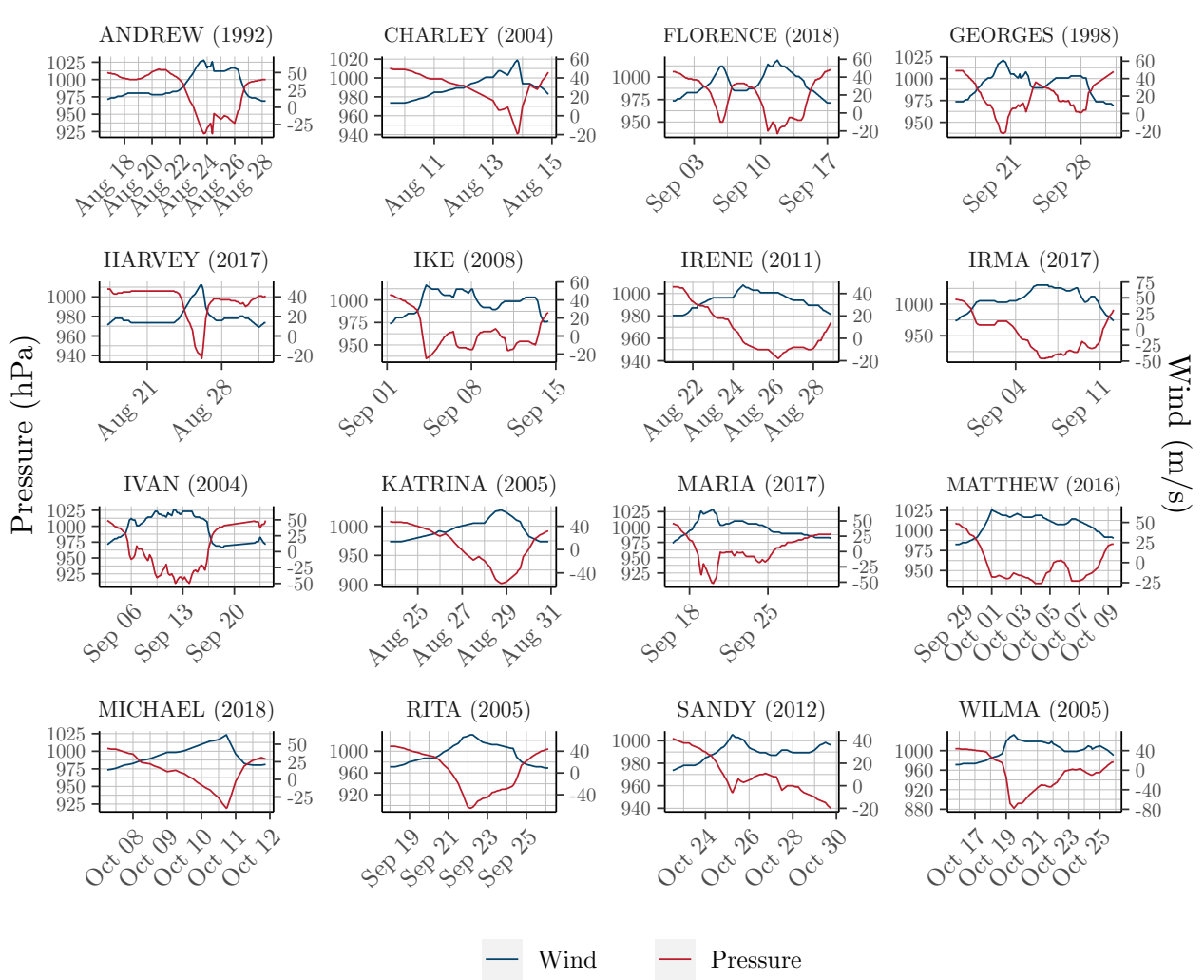

Figure 3. Central pressure and maximum wind speed evolution for most damaging named cyclones in the North Atlantic (NA) basin. The values are retrieved from IBTrACS.

the population $P_{p i x}$ per pixel - from Gridded Population of the World (GPW) database (Center for International Earth Science Information Network (CIESIN), 2017) in 2015 at the 30 arc-sec resolution for 224 countries, and various additional sources ${ }^{7}$ allowing to define the total asset $\left(A_{t o t}\right)$ for each country. This value is distributed to each grid cell proportionally to the light intensity $L_{i}$ times the local population $P_{p i x}{ }^{8}$ :

$A_{p i x}=A_{t o t} \frac{L_{i} \cdot P_{p i x}}{\sum_{p i x_{i}}^{N}\left(L_{i} \cdot P_{p i x_{i}}\right)}$.

The physical asset value is expressed in USD as of 2014. Using this dataset in the future might require correcting (either simulated or reported damages) by inflation using for instance consumer price index 9 .

\footnotetext{
${ }^{7}$ Produced Capital, comprehensive global estimate of produced capital stock, i.e. the value of produced or manufactured assets per country (World Bank, 2018) - 2014 / 140 countries; the GDP to wealth ratio from Global Wealth Report (Credit Suisse Research Institute, 2017) - 2017 / 84 countries; the gross domestic product (GDP) per country from World Bank Open Data portal (World Bank, 2019b) - 2014 / 224 countries and Subnational equivalent of GDP (GRP) from varying sources - 2012-2017 / 504 regions in 14 countries.

${ }^{8}$ The values of $A_{\text {pix }}$ on a 30 arc-second grid are available at https://www.research-collection.ethz.ch/handle/20.500.11850/331316.

${ }^{9}$ Available at: https://fred.stlouisfed.org.
} 


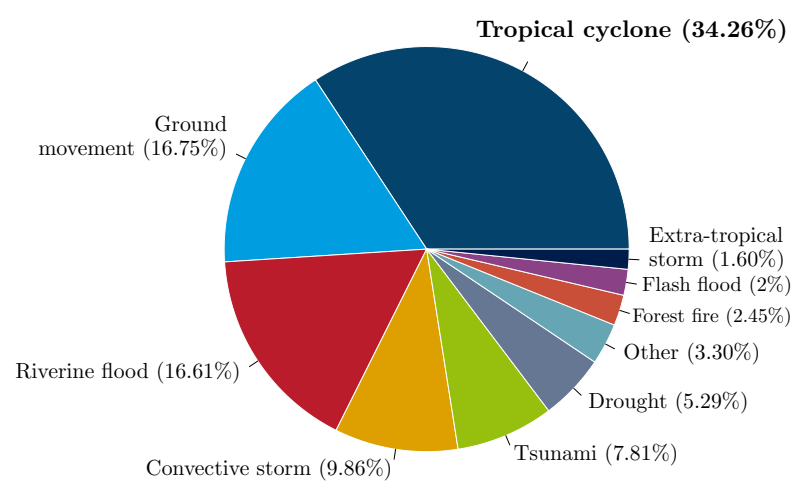

Figure 4. Proportion of damage cost (total damage in USD) by disaster subtypes reported in EM-DAT. Using the number of people affected places tropical cyclones after riverine floods and droughts, and the number of deaths places ground movements in first position (see Table A1 for details).

\subsection{Global disaster database (EM-DAT)}

The fitting of the damage functions was performed by Eberenz et al. (2020a) on reported damages in the EM-DAT database (Guha-Sapir et al., 2018) ${ }^{10}$. Filtering the database by sub-type 'tropial cyclone' allows to extract 1855 tropical cyclones in the period between 1980 and 2021, among which 1101 events have a reported total damage cost in USD. In terms of damage, tropical cyclones are, using the full set of observations from 1980 to 2021, the most damaging events reported (see Figure 4). This database includes a start date field (day, month and year) allowing us to map 455 events with the events reported in IBTrACS using start year and month and country ${ }^{11}$. We use this database to validate our simplified estimation process.

\section{Cyclone generation algorithm}

Our model structure follows Bloemendaal et al. (2020) with three main modeling steps: genesis, displacement of the eye and calibration of the cyclone properties. The STORM model relies on statistical relationships (James and Mason, 2005; DeMaria and Kaplan, 1994; Kaplan and DeMaria, 1995). This simulation method differs from the purely thermodynamic approach developed by Kerry Emmanuel (Emanuel, 1999; Emanuel et al., 2008).

\footnotetext{
10 available at : www.emdat.be.

${ }^{11}$ Eberenz et al. (2020a) functions are fitted on a similar sample of 376 tropical cyclones used for calibration.
} 


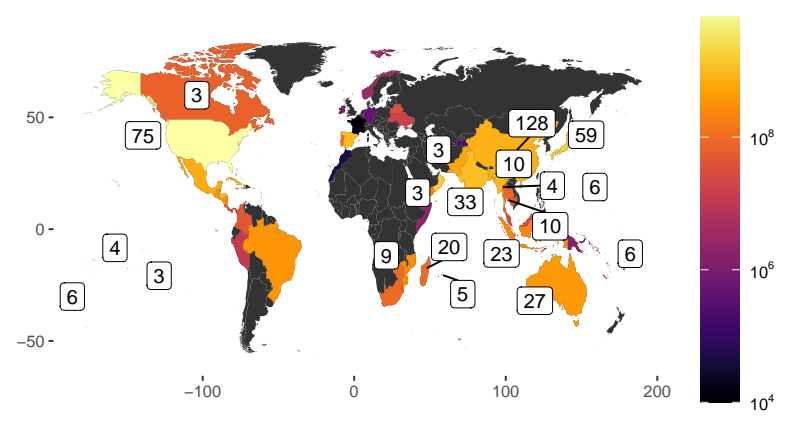

Figure 5. Number of tropical cyclones with reported damage cost in EM-DAT database. The color scale indicates the average reported damage cost in USD in each country for each tropical cyclone. available thermodynamic intensity (MPI) based on climate data. In particular, we use relative humidity (RH) and tropopause temperature (at $50 \mathrm{hPa}, T_{\text {tropo }}$ ), for better representation of the physics underlying the intensification process. In this section, we present process of generating synthetics tracks, characterized by the maximum wind $\left(V_{t}\right)$ and central pressure $\left(P_{t}^{c}\right)$ at each time step, given the climate conditions extracted from climate models.

\subsection{Cyclone genesis}

Although thermodynamic descriptions of cyclone genesis exist in the literature (Gray, 1975; DeMaria et al., 2001), there is still too much uncertainty about how climate change will affect the frequency of cyclones to justify the integration of multiple additional variables at this step. For this reason, we choose to rely on a simple statistical model based on past frequencies for the genesis. The number of synthetic cyclones each year is determined by the Poisson distribution in each basin, with parameter $\lambda_{B}$ defined as the average number of cyclones per year in the historical data. We use the parameters $\lambda_{B}$ given in Bloemendaal et al. (2020) i.e. 14.5 for the East Pacific (EP), 10.8 for the North Atlantic (NA), 2.0 for the North Indian (NI), 12.3 for the South Indian (SI), 9.3 for the South Pacific (SP), and 22.5 for the West Pacific (WP) ${ }^{12}$. Similarly, the temporal and spatial initial positions of synthetic future cyclones (longitude $x$, latitude $y$ and starting month $m$ ) are generated by independent sampling from the historical distribution of these variables. Figure 6 shows the geographical distribution of cyclones retrieved from IBTrACS (i.e. $\left.x_{o b s}, y_{o b s}\right)$ and the histograms in Figure 7 show the monthly distribution $\left(m_{o b s}\right)$ of cyclones in each basin.

\subsection{Cyclone trajectories}

A rich literature focuses on cyclone tracking algorithms, see e.g., Neu et al. (2013) for a comprehensive review. Although more advanced definitions have been proposed (Hall and Jewson, 2007; Fabregat et al., 2016), we choose, in line with Bloemendaal et al. (2020), to implement a simple auto-regressive model for cyclone coordinates. Following James and Mason (2005), the

\footnotetext{
${ }^{12}$ The parameters $\lambda_{B}$ would have been smaller if estimated using our filtered database. However, we maintain these parameters to take into consideration the fact that some events will be generated in conditions not favorable for the development of cyclones, and be cleared out of the database.
} 


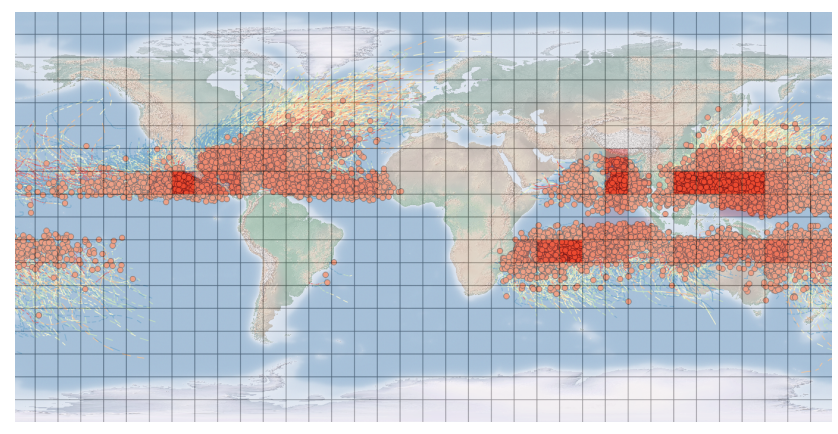

Figure 6. Spatial distribution of genesis points (all cyclones in IBTrACS). Made with Natural Earth.

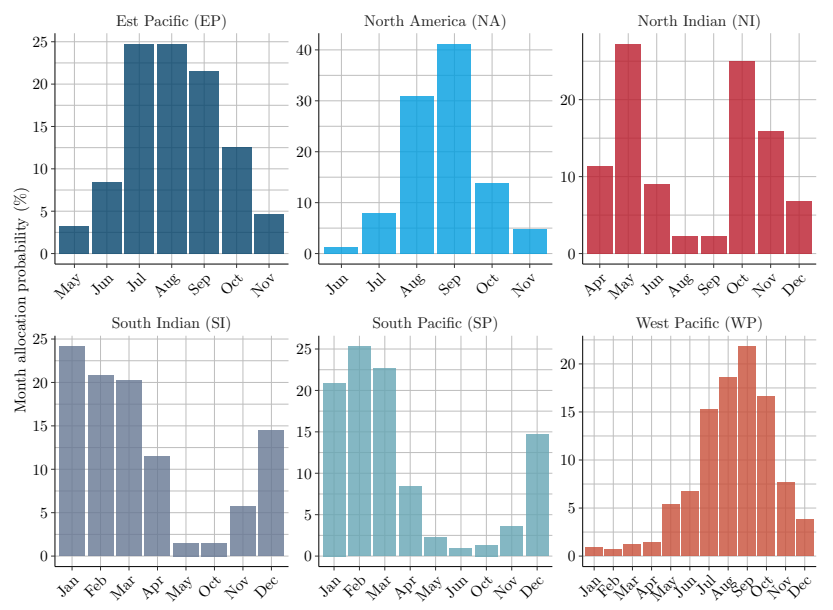

Figure 7. Relative monthly distribution (\%) of cyclones in each basin defined from potentially damaging cyclones filtration in IBTrACS. Each bar gives the probability for each cyclone to be allocated to a given month.

time evolution of the latitude and longitude of the cyclone center is described by the following stochastic dynamics:

$\Delta x_{t}=a_{0}+a_{1} \Delta x_{t-1}+\varepsilon_{t}^{x}$,

$$
\begin{aligned}
\varepsilon_{t}^{x} & \sim \mathcal{N}\left(0, \sigma_{x}\right), \\
\varepsilon_{t}^{y} & \sim \mathcal{N}\left(0, \sigma_{y}\right) .
\end{aligned}
$$

Here $x_{t}$ and $y_{t}$ are the latitude and longitude of the cyclone center sampled with a 3 hour time step; $\Delta x_{t}=x_{t}-x_{t-1}, \Delta y_{t}=$ $y_{t}-y_{t-1}, \varepsilon_{t}^{x}$ and $\varepsilon_{t}^{y}$ are i.i.d. noises independent from one another, and the constants $a_{0}, a_{1}, b_{0}, b_{1}, b_{2}, \sigma_{x}$ and $\sigma_{y}$ are fitted on IBTrACS data independently for each basin by least squares regression. Their values are provided in the Appendix. The nonlinear term in the incremental variation of the latitude is justified by the tendency for cyclones to move away from the equator, especially at very low latitudes (James and Mason, 2005, p. 183). 


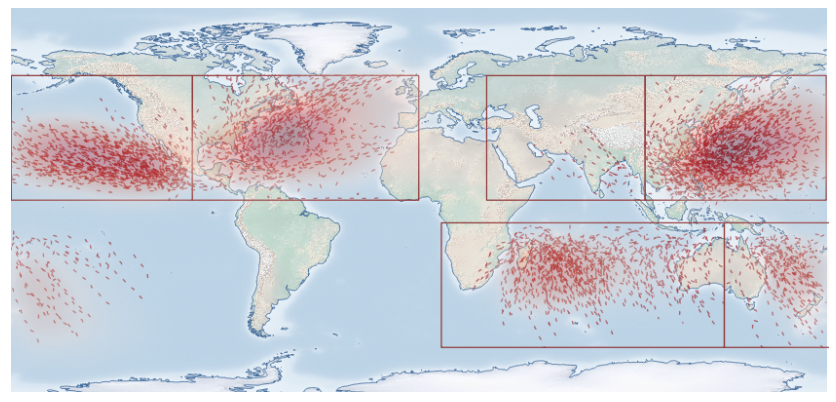

Figure 8. Synthetic tracks generated with ERA-5 climate data for the period 1980-2010. Made with Natural Earth.

We found this formulation sufficient for global assessment despite its lack of consideration for dependencies in the latitudinal and longitudinal variations (James and Mason, 2006) ${ }^{13}$. A sample of the resulting tracks is provided in Figure 8.

\subsection{Thermodynamic description of cyclone intensity}

The intensity of cyclones in our model is defined through the following five steps described in the subsequent paragraphs. The wind-pressure relationship (WPR) links the central pressure to the maximum 10 minute-sustained wind speed. The maximum potential intensity (MPI) is determined from local meteorological variables. The maximum pressure drop (MPD) is determined from historically observed pressures. The depression dynamics (DD) along tracks is defined using an autoregressive stochastic equation. When the cyclone arrives on land, a statistical decay relationship (SDR) dictates the evolution.

\subsubsection{Wind-pressure relationship (WPR)}

We describe the cyclone intensity through its central pressure $P_{t}^{c}$, which is linked with the maximum wind through an empirical relationship. Let $V_{t}$ be the maximum 10-min sustained wind speed (in $\mathrm{m} . \mathrm{s}^{-1}$ ) $^{14}$ of the cyclone at time $t$. This maximum wind is observed around $50 \mathrm{~km}$ away from the storm center on average ${ }^{15}$ and reported in IBTrACS dataset for historically observed cyclones. The wind-pressure relationship (WPR) is calibrated on the whole cyclone database as follows:

$V_{t}=a\left(P_{e n v}\left(x_{t}, y_{t}, t\right)-P_{t}^{c}\right)^{b}$

where $P_{\text {env }}(x, y, t)$ is the mean sea level pressure (MSLP) extracted $500 \mathrm{~km}$ away from the eye location at this time in ERA-5 and $P_{t}^{c}$ is the central pressure extracted from IBTrACS. This relationship is illustrated in Figure 9 and the parameters $a$ and $b$ are fitted on ERA-5 and IBTrACS data using nonlinear least squares.

\footnotetext{
${ }^{13}$ To reduce this effect and better encompass the dependency of the cyclone displacement on the location of the eye, and following Bloemendaal et al. (2020), we fitted these relationships locally using an additional grouping by $5^{\circ}$ longitude and latitude sections.

${ }^{14}$ For the data from the World Meteorological Organisation (WMO) and the agencies reporting 1 or 3-minutes sustained wind speed, we performed the conversion to 10 minutes sustained wind speed using the coefficients suggested by Knapp et al. (2010). See Figure A1 in the Appendix for more details about the agencies and reporting bias.

${ }^{15}$ Radii of maximum wind are also reported in IBTrACS but this information is not central for national level assessment.
} 


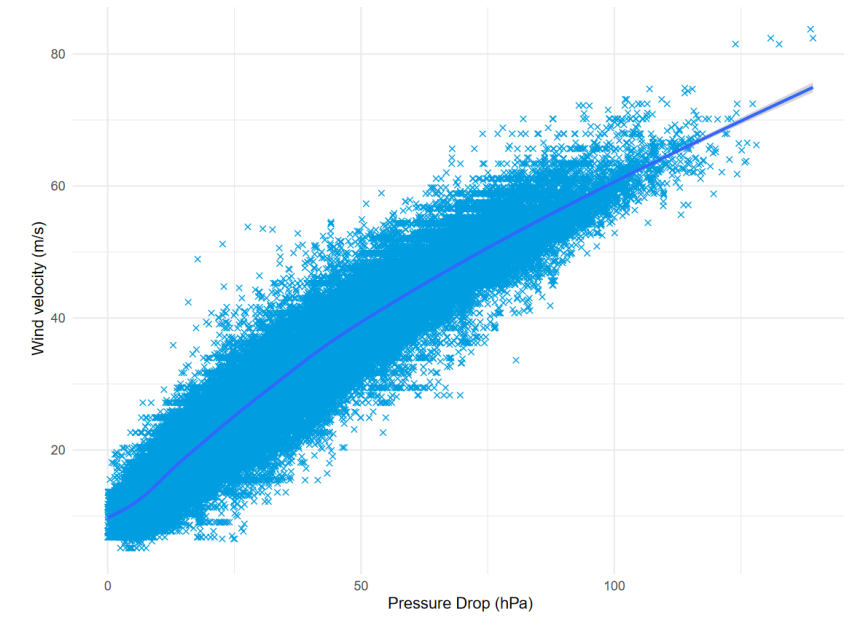

Figure 9. Maximum wind and pressure drop values from IBTrACS together with the fit of Equation (3). The parameters, $a \sim 3.8$ and $b \sim 0.6$, depend slightly on the method for filtering the cyclones.

\subsubsection{Local thermodynamic maximum potential intensity (MPI)}

We compute the local maximum potential intensity (MPI) following Holland (1997) and using thermodynamic relationships. This is particularly relevant in the context of a national damage assessment under changing climate. Indeed, greenhouse gas emissions not only warm up the oceans, but also cool down the lower stratosphere (Butchart et al., 2000; Forster et al., 2007; Ramaswamy et al., 2006). Thus, the tropopause temperature $T_{\text {tropo }}$ (that is, temperature corresponding to a pressure of 50 $\mathrm{hPa}$ or to an altitude of approximately $20 \mathrm{~km}$ ) ) must be included in the modeling of the intensification process. Indeed, the thermodynamic efficiency factor $\mathcal{E}_{t}$ proportional to the difference between tropopause and sea surface temperatures plays an essential role in the determination of the central pressure of tropical cyclone. The relative humidity $(\mathrm{RH})$ is also an influential parameter allowing for a better description of MPI ${ }^{16}$. Adding these two climate variables allows the CATHERINA model to better take into account the additional energy potential due to the widening of temperature difference between sea surface and upper troposphere and variation in moist entropy.

\footnotetext{
${ }^{16}$ In addition this parameter changes with climate change (Sherwood et al., 2010).
} 
Following the seminal formulation in Emanuel (1988) and integrating additional simplifications proposed in the subsequent paper (Emanuel, 1991) to simplify the expression, leads to the following framework summarized in Holland (1997).

$$
\begin{aligned}
\mathrm{MPI}_{t} & =\operatorname{MSLP}\left(x_{t}, y_{t}, t\right) \cdot \exp ^{-X_{t}}, \\
X_{t} & =\frac{\mathcal{E}_{t} \cdot \operatorname{SST}\left(x_{t}, y_{t}, t\right) \cdot \Delta S_{t}^{m}-\frac{f\left(y_{t}\right)^{2} r_{e n v}^{2}}{4}}{R_{d} \cdot \operatorname{SST}\left(x_{t}, y_{t}, t\right)}, \\
210 \mathcal{E}_{t} & =\frac{\operatorname{SST}\left(x_{t}, y_{t}, t\right)-T_{\text {tropo }}\left(x_{t}, y_{t}, t\right)}{\operatorname{SST}\left(x_{t}, y_{t}, t\right)}, \\
\Delta S_{t}^{m} & =R_{d} \ln \left(\frac{\operatorname{MSLP}\left(x_{t}, y_{t}, t\right)}{P_{t-1}^{c}}\right)+\frac{L_{v}\left(q_{c t}^{\star}-q_{t}^{e n v}\right)}{\operatorname{SST}\left(x_{t}, y_{t}, t\right)}, \\
q_{c t}^{\star} & =\frac{3.08}{P_{t-1}^{c}} \exp \left(\frac{\left(\operatorname{SST}\left(x_{t}, y_{t}, t\right)-273.15\right)}{\operatorname{SST}\left(x_{t}, y_{t}, t\right)-29.65}\right), \\
q_{t}^{e n v} & =\frac{3.08 \cdot \operatorname{RH}\left(x_{t}, y_{t}, t\right)}{\operatorname{MSLP}\left(x_{t}, y_{t}, t\right)} \\
& \times \exp \left(\frac{17.67\left(\operatorname{SST}\left(x_{t}, y_{t}, t\right)-273.15\right)}{\operatorname{SST}\left(x_{t}, y_{t}, t\right)-29.65}\right) .
\end{aligned}
$$

215 where $\left(x_{t}, y_{t}, t\right)$ are the coordinates of the eye defined in Equations (1) and (2), $\operatorname{SST}\left(x_{t}, y t, t\right)$ and $T_{\text {tropo }}\left(x_{t}, y_{t}, t\right)$ are respectively the sea-surface and tropopause temperatures, $R_{d}=287.058 \mathrm{~J} \cdot \mathrm{kg}^{-1} \cdot \mathrm{K}^{-1}$ is the specific gas constant for dry air, $\operatorname{MSLP}\left(x_{t}, y_{t}, t\right)$ is the mean local sea level pressure, $\mathrm{RH}\left(x_{t}, y_{t}, t\right)$ is the near surface relative humidity at 2 meters extracted from the monthly dataset of ERA-5 climate reanalysis or CMIP climate models. $f\left(y_{t}\right)=2 \omega \sin \left(y_{t}\right)$ is a Coriolis parameter depending on the latitude, $r_{\text {env }}$ is the distance between the eye and the area under regular conditions (fixed at $500 \mathrm{~km}$ ), $q_{\text {env }}$ and $q_{c}^{*}$ respectively are the specific humidity at environmental conditions and at saturation, i.e. for $\mathrm{RH}=100 \%$, in the eye. $\Delta S^{m}$ is the difference of moist entropy between the environment and the storm center and $L_{v}$ is the latent heat of vaporization. The distributions of the variables computed from ERA-5 climate variables along IBTrACS involved in this step are shown in Figure 10. The distance to MPI is computed as the difference between the central pressure and the maximum potential intensity (MPI) defined in Equation (4).

\subsubsection{Maximum pressure drop (MPD)}

Several papers, including Bloemendaal et al. (2020), link the sea surface temperature directly to the pressure drop, or equivalently the wind speed, via a statistical relationship (DeMaria and Kaplan, 1994). Merrill (1987) suggests that this predictor alone does not provide a good indication whether a given storm will intensify. However, in line with Emanuel (1988) and DeMaria and Kaplan (1994) the sea surface temperature can be used to fix a limit for the pressure drop. More precisely, to prevent the pressure drop from diverging in the projection, we cap it by the maximum observed pressure drop for the corresponding sea surface temperature:

$P_{t}^{c}:=\max \left(P_{t}^{c}, \operatorname{MSLP}\left(x_{t}, y_{t}, t\right)-\operatorname{MPD}\left(\operatorname{SST}\left(x_{t}, y_{t}, t\right)\right)\right)$, 

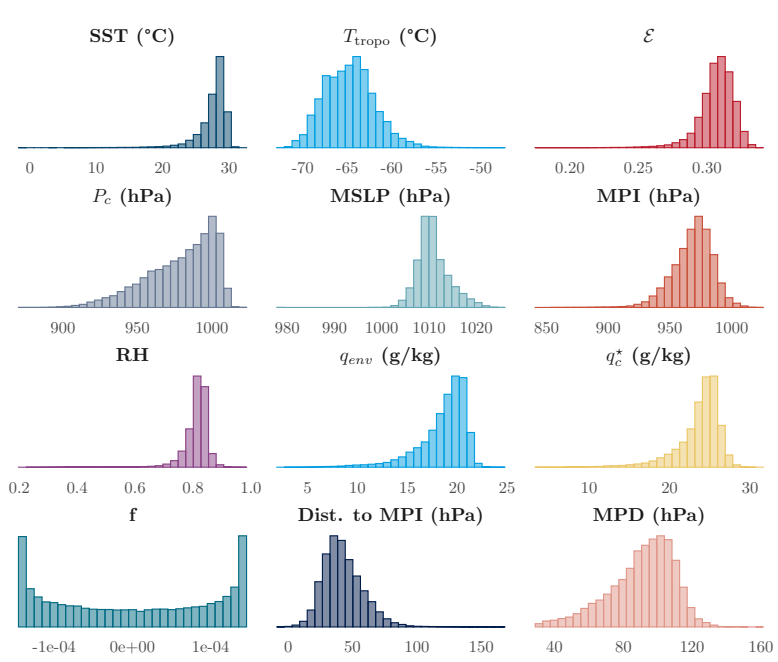

Figure 10. Empirical distribution of physical properties along tracks (IBTrACS and ERA-5)

where the maximum pressure drop function is given by the following equation:

$\operatorname{MPD}(\mathrm{SST})=A+B \cdot e^{C\left(\operatorname{SST}\left(x_{t}, y_{t}, t\right)-T_{0}\right)}$

with $T_{0}=30.0^{\circ} \mathrm{C}$. To fit this functional relationship, we first retrieve, for each basin, and for each value of the sea surface temperature SST, rounded at 0.1, the maximum observed value of pressure drop in the basin. These values are shown as crosses in Figure 11. The coefficients $A, B$ and $C$ from relationship (10) are then fitted to these values by nonlinear least squares. The resulting MPD functions for each basin are shown in Figure 11 as solid lines.

Figure 11 gives a somewhat misleading idea about the strength of correlation between the sea surface temperature and the central pressure: indeed, fitting the distribution on the full sample (instead of just the maximum pressure drop for each temperature value) shows a much weaker influence of sea surface temperature alone, even on a weekly basis (see Jien et al. (2017) and Figure A3 in the Appendix). However, this instrumental variable is essential to prevent CATHERINA from producing unrealistically low central pressure.

\subsubsection{Depression dynamics (DD)}

245 The evolution of the central pressure depending on local MPI is described by the following autoregressive stochastic depression dynamics (James and Mason, 2005):

$\Delta P_{t}^{c}=c_{0}+c_{1} \Delta P_{t-1}^{c}+c_{2} e^{-c_{3}\left[P_{t}^{c}-\mathrm{MPI}_{t}\right]}+\varepsilon_{t}^{P}$,

$\varepsilon_{t}^{P} \sim \mathcal{N}\left(0, \sigma_{P^{c}}\right)$,

where the distance to maximum potential, $P_{t}^{c}-\mathrm{MPI}_{t}$, enters as a non-linear term in the dynamic definition of the central pressure "providing an increasing tendency for $\Delta p$ to be positive as the central pressure approaches the mean MPI for the 


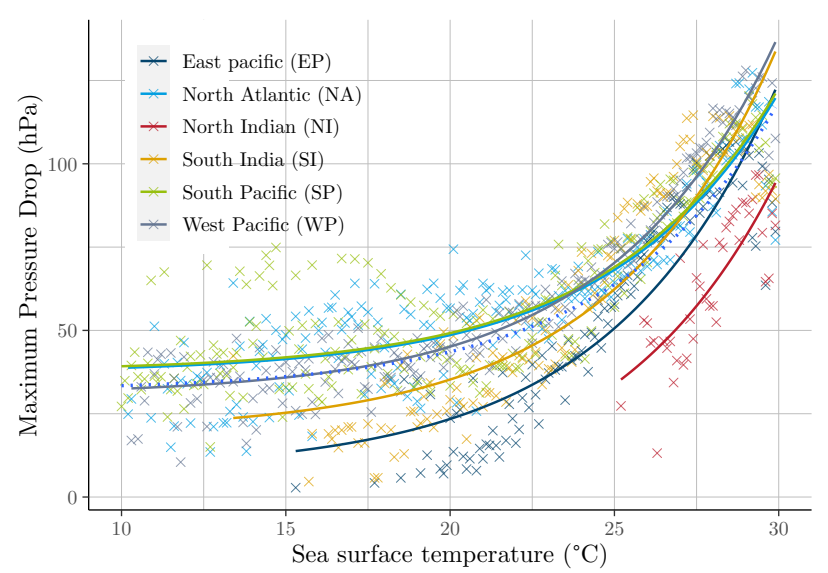

Figure 11. Maximum observed pressure drop values for given SST (crosses) and the fit of equation Equation (10) for each basin (solid lines). The dotted line shows the calibration of Equation (10) simultaneously to all basins $(A=30.6, B=86.3$ and $C=0.19$ ).

Table 2. James and Mason (2005) depression dynamics (Equation 11) parameters, standard errors and confidence intervals estimated using nonlinear least squares on the full sample. The MPI is computed based on the climate data extracted along tracks from ERA-5, and the depression dynamics are derived from IBTrACS

\begin{tabular}{|l|r|r|r|r|}
\hline & Estimate & Std. Error & $2.5 \%$ & $97.5 \%$ \\
\hline$c_{0}$ & 17.966 & 3.1618 & 11.770 & 24.162 \\
$c_{1}$ & -0.516 & 0.00274 & -0.522 & -0.510 \\
$c_{2}$ & -19.528 & 3.180 & -25.760 & -13.295 \\
$c_{3}$ & 0.00776 & 0.00134 & 0.005 & 0.010 \\
\hline
\end{tabular}

cyclone's location" (James and Mason, 2005, p. 183). The parameters are fitted on historical tracks using ERA-5 reanalysis with nonlinear least squares (see Table 2). The confidence intervals show non-negligible variations, however, the coefficients remain statistically significant and of the expected sign. This relationship channels the effect of global warming, affecting the maximum potential intensity, on the cyclone intensity. In other words, the incremental variation of the central depression of the cyclone is linked to the difference between the central pressure at time $t$ and the potential available in the environment.

\subsubsection{Statistical decay relationship (SDR) over land}

We model the evolution of the cyclone after landfall using an exponential decay function considering that "tropical cyclone intensity decreases as a function of the time and distance the tropical cyclone has covered whilst being over land" (Kaplan and 

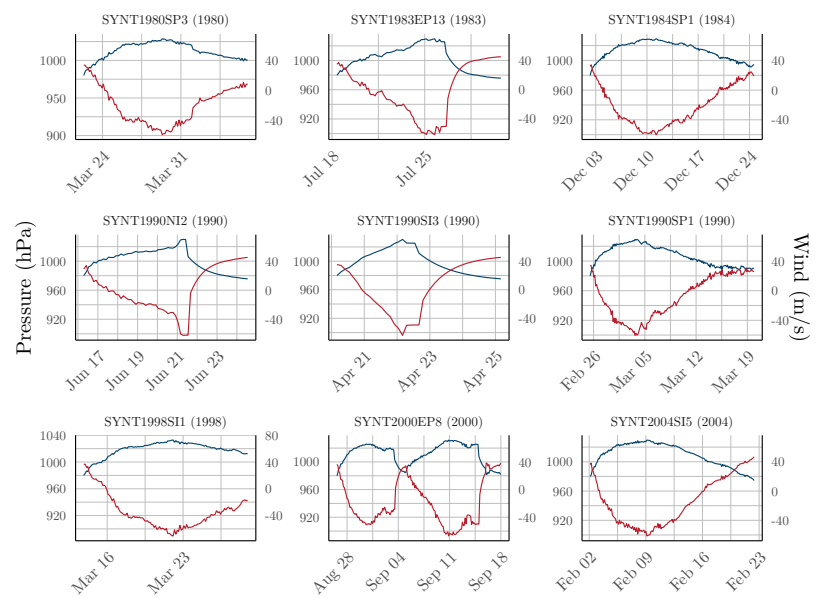

- Wind - Pressure

Figure 12. Depression and wind evolution over cyclones lifetime (top winds in synthetic tracks). We observe similar dynamics as in Figures 2 and 3 .

DeMaria, 1995). Similarly to Bloemendaal et al. (2020), after three steps on land we suppose that the wind at time $t_{L}$ follows:

$$
\begin{aligned}
V_{t_{L}} & =V_{b}+\left(R \cdot V_{0}-V_{b}\right) e^{-\alpha t_{L}}-f_{1}\left(t_{L}\right)\left(\ln \frac{D^{l}}{D_{0}}\right)+f_{2}\left(t_{L}\right) \\
& =V\left(t_{L}, D^{l}, V_{0}\right)
\end{aligned}
$$

where $D^{l}$ is the distance to coast computed using natural earth coastlines ${ }^{17}, V_{0}$ is the wind at landfall and $t_{L}$ the time spent on land by the eye. This function was fitted on IBTrACS using nonlinear least squares. In our procedure, we use the global ${ }^{18}$ parameters: $R=0.79, V_{b}=15 \mathrm{~m} . \mathrm{s}^{-1}, \alpha=0.044 \mathrm{~h}^{-1}$, and $f_{1}\left(t_{L}\right)=\tilde{c}_{1} t_{L}\left(t_{0, L}-t_{L}\right), \tilde{c}_{1}=3.35 .10^{-4} \mathrm{~ms}^{-1} \mathrm{~h}^{-2}, t_{0, L}=172 \mathrm{~h}$, $f_{2}\left(t_{L}\right)=d_{1} t_{L}\left(t_{0, L}-t_{L}\right), d_{1}=-0.00186 \mathrm{~ms}^{-1} \mathrm{~h}^{-2}$ and $D_{0}=1 \mathrm{~km}$. Kaplan and DeMaria (1995) introduced this function to model the decay of tropical cyclone over land in a simple way and showed that it provides an acceptable approximation for $t_{L} \geqslant$ 12h. A more sophisticated description could integrate for instance, cyclone physics, kinetic energy, and non-meteorological parameters such as ground topology. The SDR puts a strong constraint on the cyclone evolution after three steps. However, in the context of national damage assessment we reiterate that reported damage costs are the combination of a series of various impacts including storm surge and not only extreme wind and that the most exposed area is at landfall. We consider therefore that the hypothesis of a rapid decay is acceptable and in line with observations.

\footnotetext{
${ }^{17}$ Available at https://www.naturalearthdata.com/downloads/10m-physical-vectors/.

${ }^{18}$ The statistical parameters are stable and fitting this relationships with non-linear least square for each basin gives the parameters in Table A8 on page 43 .
} 


\subsection{Cyclone generation algorithm}

The full cyclone generation procedure is presented in Algorithm 1. The cyclone wind speed is initiated at $20 \mathrm{~m} \cdot \mathrm{s}^{-1}$ and the initial pressure is determined from the WPR (Equation (3)). While the cyclone is over sea, the pressure evolution $\Delta P_{c}$ is entirely determined from Equation (11) based on the local MPI. To prevent the model from producing unrealistically low central pressure, we cap the maximum pressure drop (MPD) using Equation (10). With this truncation the lower bound for the pressure is given by the observed low pressure values in similar sea-surface temperature conditions. While the cyclone is over sea, the wind is defined with the WPR (Equation (3)). When the cyclone arrives on land the MPI is computed from the last known climate variables for the first three steps and the pressure still follows the relationship (11). After three steps (9h) on land, we start applying the decay relationship (Equation (13)) to define the wind. The variations of longitude and latitude are always defined using Equation (1) and Equation (2). We force cyclones to remain in their genesis basins in this exercise.

\section{Damage assessment at the national level}

\subsection{Damage modeling}

The percentage of asset value destroyed by a tropical cyclone depends of multiple parameters. For example, to assess the vulnerability of specific infrastructures to tropical cyclones, precise descriptions of building vulnerability are provided in the Federal Emergency Management Agency (FEMA) reports. Unanwa et al. (2000) propose a series of wind damage bands depending on building types. For commercial and institutional buildings the sensitivity is higher than for residential and midrise buildings. This study reveals that generalized damages occur above $43-60 \mathrm{~m} . \mathrm{s}^{-1}$. Sustained wind regime above $73 \mathrm{~m} . \mathrm{s}^{-1}$ could lead to the destruction of the entire superstructure of most buildings (expect for mid and low-rise). Damages provoked by winds between 60 and $81 \mathrm{~m} \cdot \mathrm{s}^{-1}$ strongly depend on components and connections. These bottom-up approaches allow us to set the limits of the potential damage functions, but their use requires a complete inventory of assets and up-to-date values of numerous parameters (age, height, materials, etc.). Therefore, CATHERINA relies on regional damage functions calibrated by Eberenz et al. (2020a) on wind speed along cyclone track (IBTrACS) and reported damages in Guha-Sapir et al. (2018).

\subsection{From an explicit damage function...}

Damage functions can take several different forms (Prahl et al., 2015) but the most common choice is a cubic functional of the wind speed. To estimate the fraction of loss from a storm with sustained wind speed $V$, Emanuel (2011) introduced the following formula:

$f\left(V, v_{h}^{j}\right)=\frac{\left(\max \left(V-v_{0}, 0\right)\right)^{3}}{\left(v_{h}^{j}-v_{0}\right)^{3}+\left(\max \left(V-v_{0}, 0\right)\right)^{3}}$,

where $f$ is the fraction of the property value lost, $v_{0}=25.7 \mathrm{~m} \cdot \mathrm{s}^{-1}$ and $v_{h}^{j}$ a parameter that needs to be calibrated for each region $j$. 


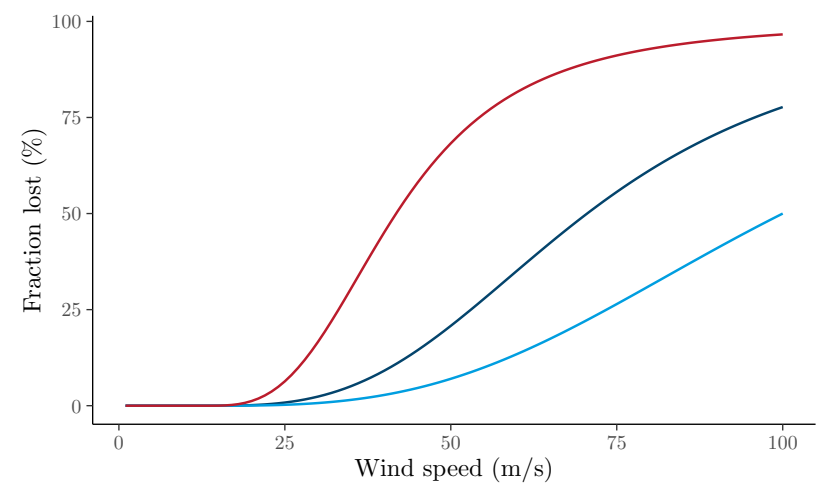

Figure 13. Fraction of property value lost as a function of wind speed, obtained using Equation (14) with $v_{h}^{j}=50$ (red), 74.4 (dark blue) and $100 \mathrm{~m} \cdot \mathrm{s}^{-1}$ (light blue)

\section{3 ... to a regional damage calibration}

Using the reported damage estimates from the International Disaster Database (EM-DAT) crossed with cyclone tracks (IBTrACS), and geographical and socio-economic information along these tracks, Lüthi (2019) refined the damage function approach using machine learning techniques introducing region-specific damage functions.

We recall the main steps of the methodology presented in (Lüthi, 2019; Eberenz et al., 2020a) to define the regional damage functions. The authors first defined the event damage ratio (EDR) as a ratio of simulated damage (SED) to normalized reported damage (NRD) for each cyclone:

$$
\operatorname{EDR}(i, j)=\frac{\operatorname{SED}\left(i, v_{h}(j)\right)}{\operatorname{NRD}(i)}
$$

The total damage ratio (TDR) is then defined in each region summing over events:

$$
\operatorname{TDR}(j)=\frac{\sum_{i} \operatorname{SED}\left(i, v_{h}(j)\right)}{\sum_{i} \operatorname{NRD}(i)}
$$

For each event, there is a value for $v_{h}$ allowing to optimally calibrate the explicit damage function given in Equation (14). The relatively wide distribution of $v_{h}$ for the same country shows that there is a large uncertainty in the relationship between the wind speed and the corresponding fraction of losses ${ }^{19}$.

The authors propose two alternative optimization methodologies to find the value of $v_{h}^{\star}$ maximizing the prediction quality of the regional damages: root mean square fraction (RMSF), minimizing the spread of the event damage ratios (EDR); and total damage ratio (TDR), finding the value of $v_{h}^{\star}$, such that the ratio of total simulated damage - obtained summing over event damages - and total reported damage tends to 1 . The values of $v_{h}$ obtained with the two methods are given in Table 3 . For most regions the optimized curves are similar for the two optimization techniques, but the results diverge for the Philippines (WP2) and to a lesser extend for China Mainland (WP3) events. The case of the Philippines, discussed in Eberenz et al. (2020a),

\footnotetext{
${ }^{19}$ In the Appendix, Figure A4 shows the uncertainty in regional damage functions depending on the optimization technique used and Figure A5 allows us to appreciate, for countries where more than 5 cyclones were reported, the spread of plausible damage functions.
} 
Table 3. Values of $v_{h}$ obtained using TDR and RMSF methods for each region from the CLIMADA environment

\begin{tabular}{lrr}
\hline Region & $v_{h}{ }_{\mathrm{TDR}}^{\star}$ & $v_{h}{ }_{\mathrm{RMSF}}^{\star}$ \\
\hline Caribbean and Mexico (NA1) & 58.8 & 59.6 \\
China Mainland (WP3) & 101.5 & 80.2 \\
USA and Canada (NA2) & 80.5 & 86 \\
North Indian (NI) & 63.7 & 58.7 \\
South East Asia (WP1) & 60.7 & 56.7 \\
North West Pacific (WP4) & 169.6 & 135.6 \\
Philippines (WP2) & 167.5 & 84.7 \\
Oceania (OC) & 56.8 & 49.7 \\
South Indian (SI) & 48.5 & 46.8 \\
Global (GLB) & 98.9 & 73.4 \\
\hline Coefficient from version 1.5 of the CLIMADA environment. Figure A4 \\
also illustrate the shapes of the functions for the different optimization \\
problems (RMSF vs. TDR) and version (1.0 vs 1.5).
\end{tabular}

is explained by the large number of parameters involved in the damage estimation, and emphasizes two main limitations of the model: first, this framework lacks an explicit representation of sub-perils which disrupt and damage several sectors and services, and second, differences in exposure and vulnerability between urban and rural areas exposed to TCs are likely to contribute to the large spread in EDR.

\subsection{Simplified estimation along tracks}

In the context of our national level assessment, we propose a simplified damage module. The simulated damage for a given cyclone - in both IBTrACS and our synthetic tracks - is computed using the following procedure for each individual cyclone. First, a uniform grid with step given by the average cyclone radius is defined on the map of affected area. The cyclone track is linearly interpolated, and the tiles affected by the cyclone (containing a part of the interpolated path) are identified (see Figure 14). Second, for each tile identified in the previous step, we retrieve the maximum wind speed $V$, and compute the proportion of wealth lost $f\left(V, v_{h}^{j}\right)$ using the relation (14) with the total damage ratio parameter given in Eberenz et al. (2020a). Then, we compute the total simulated damage by aggregating the physical asset exposure multiplied by the proportion of wealth lost on each tile over all tiles affected by the cyclone.

As a result of this procedure, we obtain the total simulated damage $\operatorname{SED}_{i}(j, t)$ caused by the $i$-th cyclone in region $j$, simulated with climate variables for year $t$.

The damage functions used in the second step are retrieved directly from the CLIMADA environment. These functions were fitted with the same physical asset value, however, in our case we project these values on a coarser grid (first step), in such a way that the extraction is simplified for a large number of synthetic tracks. Figure 15 presents the estimated versus actual damages computed using the TDR damage function. We aggregate asset values on $0.25 \times 0.25^{\circ}$ grid. The average estimation 
https://doi.org/10.5194/gmd-2021-384

Preprint. Discussion started: 2 December 2021

(c) Author(s) 2021. CC BY 4.0 License.

(a) Asset data (30 arc-sec)

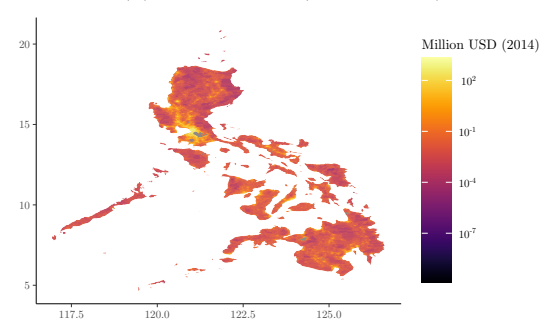

(b) Rasterized map $(0.25 \times 0.25)$

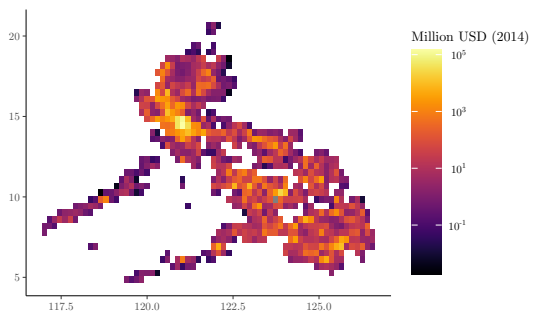

(c) Interpolation along path

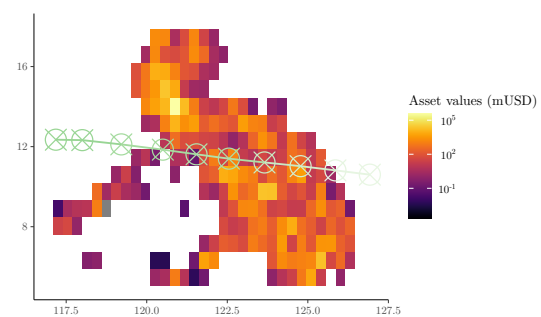

Figure 14. Illustration of the high resolution asset data (a) rasterization (b) and interpolation process (c) to evaluate asset exposure along tracks

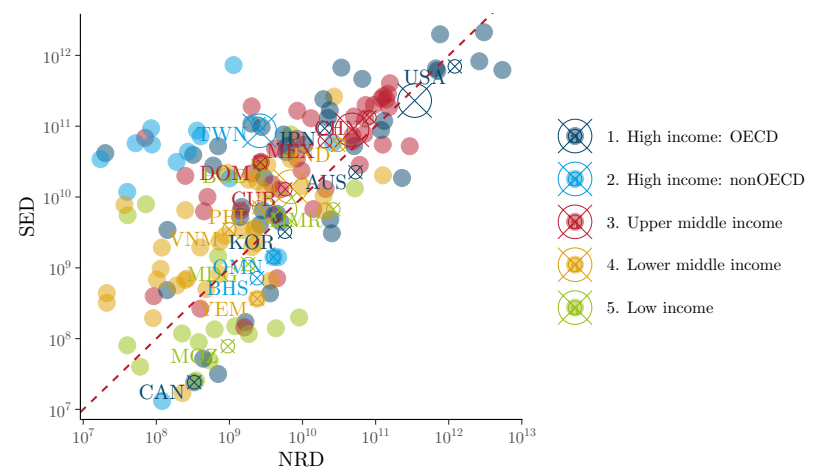

Figure 15. Estimated vs. reported damage. The filled dots represent individual events with reported damage in EM-DAT. The small targets represent countries average and large targets income groups average. This distribution is obtained using a $0.25 \mathrm{x} 0.25$ resolution projection.

over realised ratio in each region is acceptable, slightly overestimated for high income non-EOCD countries (in particular for Taiwan), using the total reported damage from EM-DAT.

Finally, the cyclone damage cost in region $j$ and year $t$ is simulated as follows:

$\mathcal{D}(j, t)=\sum_{i} \operatorname{SED}_{i}(j, t)$

where the sum is taken over all cyclones occurring in a given year. This procedure can then be repeated many times to obtain the distribution of annual cyclone damages and compute other statistics such as the mean and quantiles of this distribution. 


\section{Application to damage assessment in representative concentration pathways (RCP)}

\subsection{Climate simulation debiaising for climate change application}

The variables from climate model projections used by CATHERINA are subject to multiple biases. To reduce uncertainty caused by these biases, we use the Cumulative Distribution Function-transform (CDF-t) method developed in (Vrac et al., 2012; Michelangeli et al., 2009) to correct the distribution of each variable, in each basin.

Consider a generic climate variable (denoted by $\chi$ ) at a fixed location, which is available both from ERA5 reanalysis and from a given CMIP5 model. We are interested in two time periods: the historical period (covered both by the climate model and the reanalysis) and a future time period (covered only by the climate model). Let $F_{\mathrm{ERA} 5}^{h}$ and $F_{\mathrm{CMIP}}^{h}$ be the distribution functions of $\chi$ under reanalysis and under climate model for the historical period, and $F_{\mathrm{CMIP} 5}^{f}$ be the distribution function of $\chi$ under climate model for the future period. The distribution function under the climate model is subject to much stronger biases than that under the reanalysis. The CDF-t method constructs the distribution function for $\chi$ with reduced bias for the future time period, denoted by $\widehat{F}_{\mathrm{CMIP}}^{f}$ and given by

$$
\widehat{F}_{\mathrm{CMIP}}^{f}(\cdot)=F_{\mathrm{ERA} 5}^{h}\left(F_{\mathrm{CMIP}}^{h,-1}\left(F_{\mathrm{CMIP}}^{f}(\cdot)\right)\right),
$$

where $F_{\mathrm{CMIP}}^{h,-1}$ is the inverse function of $F_{\mathrm{CMIP}}^{h}$. For a given value $\chi_{C M I P}^{f}$ of the variable $\chi$ obtained for the future period from the climate model, the corresponding unbiased value $\hat{\chi}_{C M I P}^{f}$ may then be computed via

$$
\begin{aligned}
\hat{\chi}_{C M I P}^{f} & =\widehat{F}_{\mathrm{CMIP}}^{f,-1}\left(F_{\mathrm{CMIP}}^{f}\right) \\
& =F_{\mathrm{CMIP}}^{f,-1}\left(F_{\mathrm{CMIP}}^{h}\left(F_{\mathrm{ERA} 5}^{h,-1}\left(F_{\mathrm{CMIP}}^{f}\left(\chi_{C M I P}^{f}\right)\right)\right) .\right.
\end{aligned}
$$

When the future period and the historical period coincide, the method reduces to the standard quantile transform:

$$
\hat{\chi}_{C M I P}^{h}=F_{\mathrm{ERA5}}^{h,-1}\left(F_{\mathrm{CMIP}}^{h}\left(\chi_{C M I P}^{h}\right)\right) .
$$

First, we use the method on the historical period to compare the description of the MPI and wind speed with and without correction, so equation (16) may be used directly. To extract the CDFs, we generate synthetic tracks from 1980 (beginning of ERA-5) to $2010^{20}$. For each point in space and time along these synthetic tracks, we extract the values of the four climate variables from the reanalysis (ERA-5) and from the historical simulations of the 7 climate models. Then, by comparing the $\mathrm{CDF}$ of the climate variables estimated by the models with the reference CDF compute from the reanalysis for each grid point, we determine the transformation allowing the values estimated by the models to better match those from ERA-5.

Figure 16 shows the distribution of sea surface temperature (SST), surface pressure (MSLP), relative humidity (RH) and troposphere temperature $\left(T_{\text {tropo }}\right)$ at the same point in time in the historical runs. The sea-level pressure distributions are stable over basins and models. The tropospheric temperature and near surface relative humidity distributions depend largely on the basin and display evidence of non-negligible model uncertainty. The sea-surface temperature estimates along the same synthetic

\footnotetext{
${ }^{20}$ We launch 10 times over these 30 years to obtain at least 300 representative years.
} 
Sea surface temperature (K)

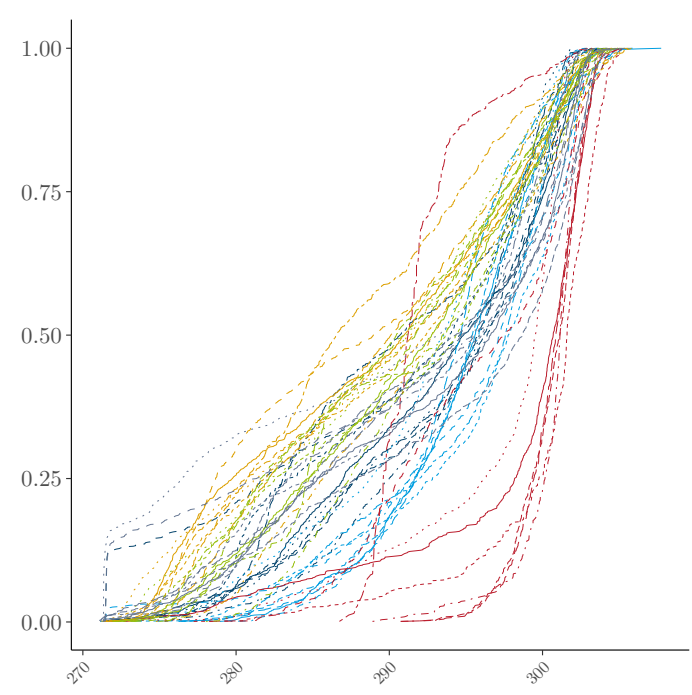

Relative humidity (\%)

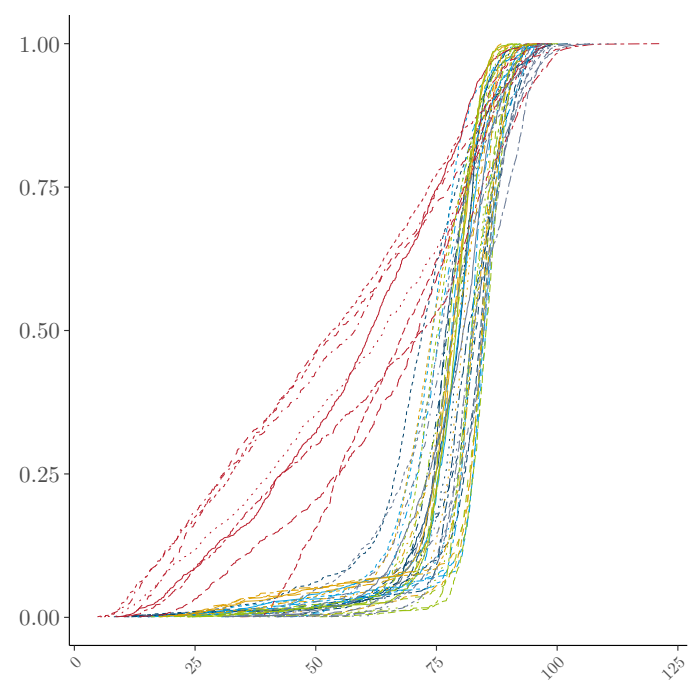

Sea level pressure $(\mathrm{hPa})$

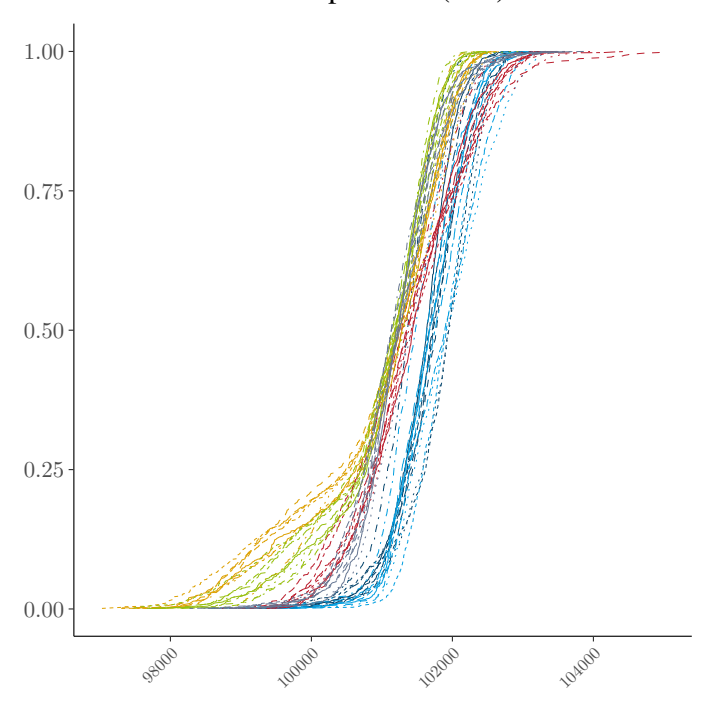

Tropopause temperature (K)

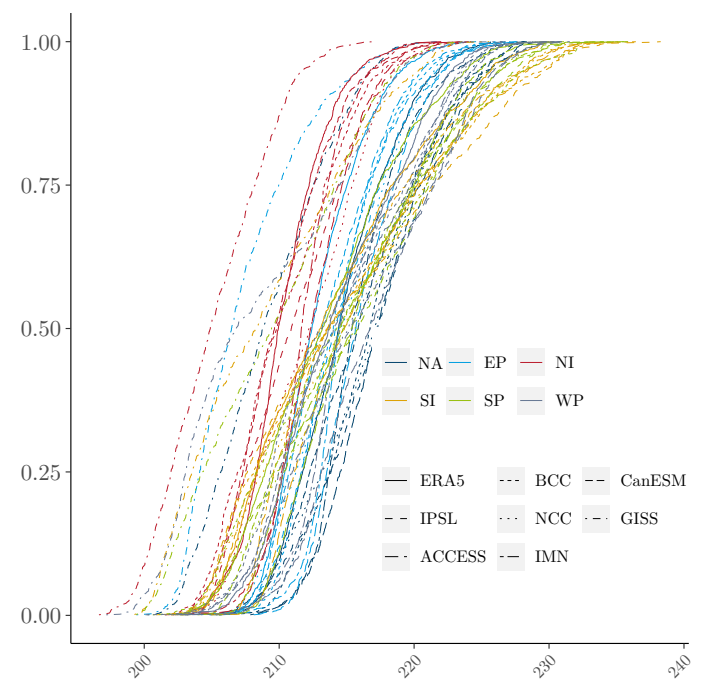

Figure 16. Cumulative distribution functions per basin for the variables of interest along synthetic tracks produced with ERA-5 and extracted (at the same location) from climate data produced by the 7 climate models.

NA: North America, EP: East Pacific, NI: North Indian, SI: South Indian, SP: South Pacific, WP: West Pacific. 

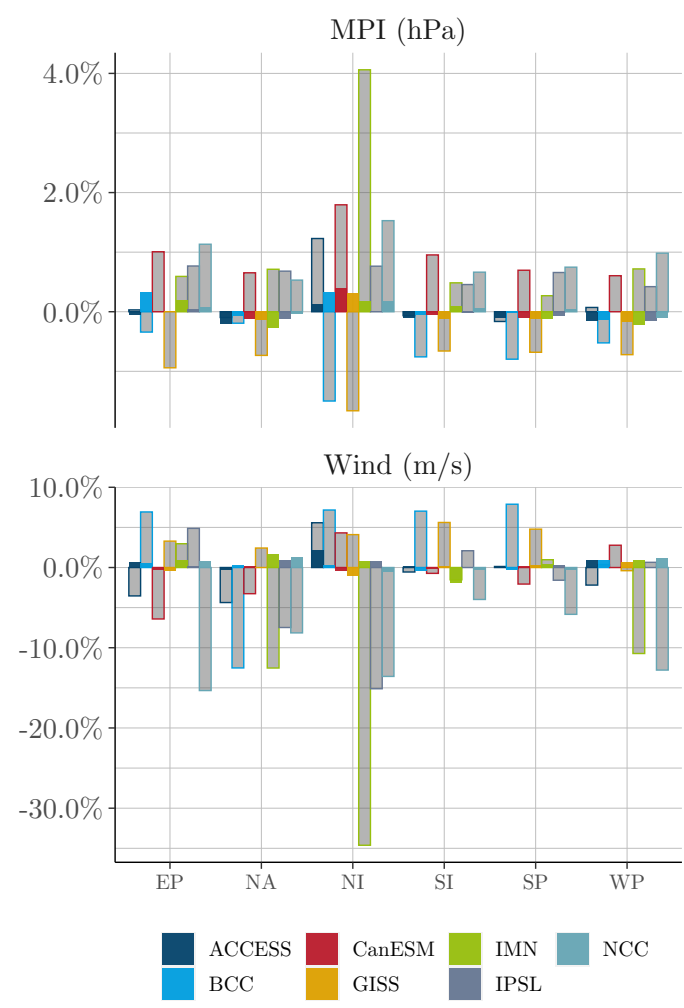

Figure 17. Relative error at the level of maximum potential intensity (MPI) and corresponding maximum wind speed computed with ERA-5 and climate data produced by the 7 climate models for the historical period. The transparent grey bars represent original errors and the color parts represent the residual relative error after CDF-t correction averaged over 30 years of cyclones.

tracks in the historical period display much larger uncertainty. The North Indian basin presents the widest uncertainty for all climate variables, which adds further uncertainty concerning the impact of climate change on tropical cyclones in this area ${ }^{21}$.

We apply the CDF-t correction technique along our historical synthetic tracks and compute the maximum potential intensity following section 3.3.3. The pressure follows the dynamic process introduced in section 3.3.4 and the corresponding wind is derived from the WPR (see section 3.3.1). We define the model error as the relative error $\left(\frac{\chi_{\mathrm{CMIP}}-\chi_{\mathrm{ERA} 5}}{\chi_{\mathrm{ERA} 5}}\right)$ between the value produced by the model and the one produced by the reanalysis ERA-5. Figure 18 displays the average relative errors and shows that a $4 \%$ relative error in the description of the maximum potential intensity can lead to a $35 \%$ error in the description of the implied wind compared to the result obtained with ERA-5. On average the CDF-t correction technique clearly reduces the error between the MPI estimated with climate reanalysis and the one computed from modeled climate data as well as (more importantly) the error in the description of the maximum wind speed. In relative terms, the average relative error is reduced by more than $65 \%$ for the MPI and $74 \%$ for the wind.

\footnotetext{
${ }^{21}$ These biases and uncertainties may be mitigated in the latest launch of the models at the occasion of the CMIP6 (Gusain et al., 2020).
} 

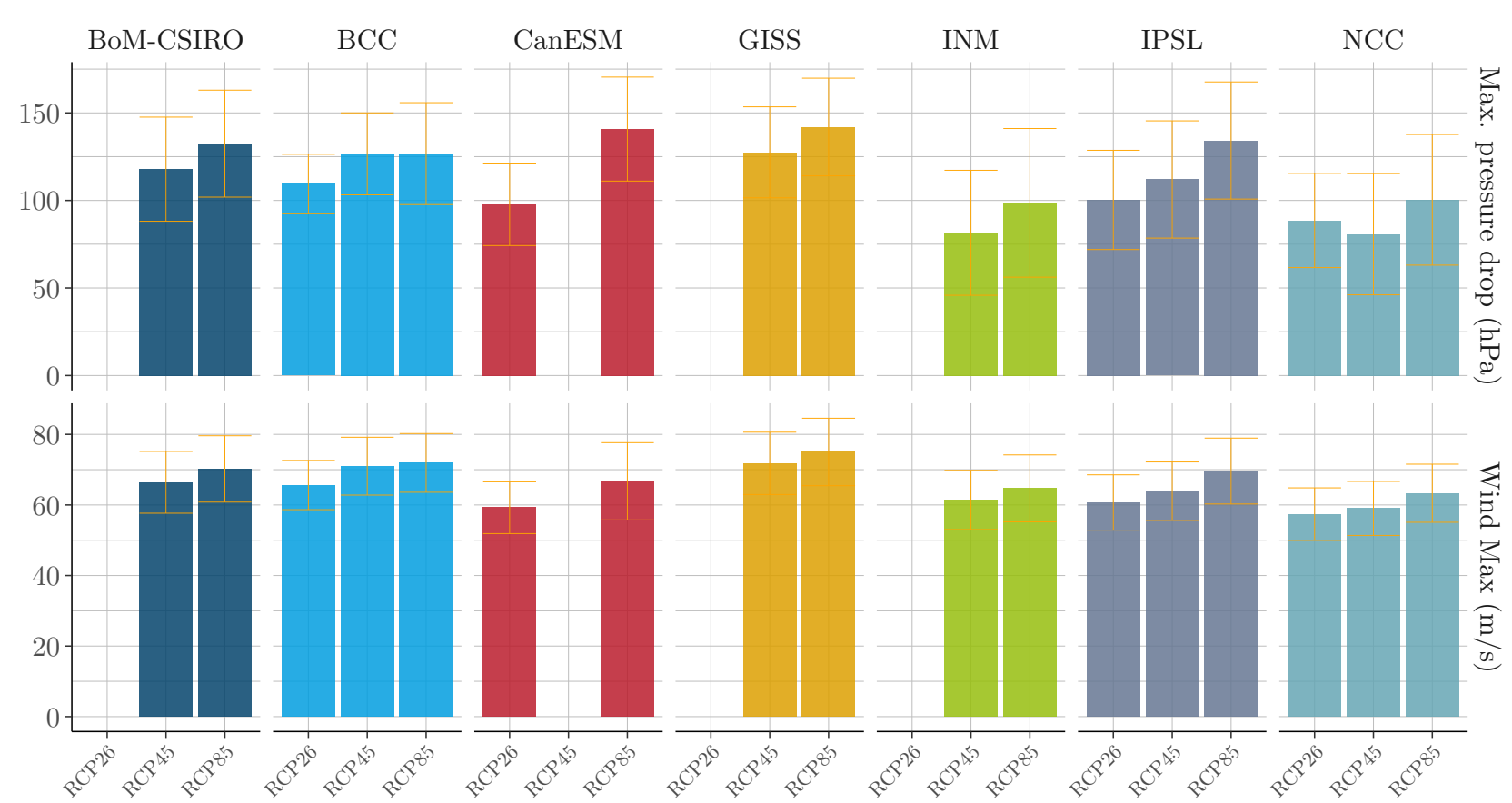

ACCESS1-0 (BoM-CSIRO, Australia) bcc-csm1-1-m (BCC, China)

CanESM2 (CCCMA, Canada) GISS-E2-H (NASA, USA)

Figure 18. Average and standard deviation of max pressure drop and maximum wind speed generated with the CMIP5 models after correction

\subsection{Results in CMIP5 projections}

The international climate modeling community introduced shared-socioeconomic pathways (SSP) to translate varying narratives on the development of the society in the long-term. These projections impact the local physical asset value dynamics (Jones and O'Neill, 2020; Chen et al., 2020), and global macroeconomic variables (O'Neill et al., 2014, 2017). Under the assumption of constant impact ratio (i.e. the damage functions remain the same), CATHERINA allows us to derive damage projections in varying climate and socio-economic scenarios. Using unbiased climate variable projections from the seven climate models over the period 2070-2100, we provide an example of application of the CATHERINA framework ${ }^{22}$.

For example, over 2070-2100, the RCP 2.6 scenario, which is in line with the Paris Agreement and keeps global warming below $2^{\circ} \mathrm{C}$ by 2100 , involves an increase in annual financial losses of $27 \%$ on average compared to the last 40 years. In the case of RCP 4.5 (between 1.7 and $3.2^{\circ} \mathrm{C}$ warming by 2100 ) and RCP 8.5 (between 3.2 and $5.4^{\circ} \mathrm{C}$ warming by 2100 ), the average expected damage increases respectively by $74 \%$ and $130 \%$. These results were obtained under the economic assumptions asso-

\footnotetext{
${ }^{22}$ Because of the time slicing of the CMIP5 climate data available in the climate data store, we launch the models on 25 consecutive years over this period: 2070-2095 for IPSL, BCC, NCC, CCCMA, 2075-2100 for GISS, 2085-2095 for INM (only a 10 year slice of climate data is available on the CDS for this model). We repeat this process changing the seed 12 times to obtain 300 representative years in each model (except INM for which we only have 120 years).
} 


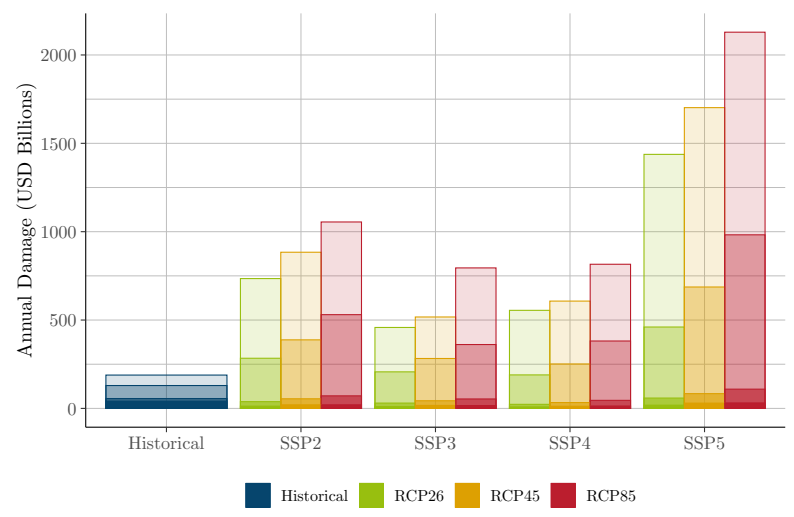

Figure 19. Annualized global damage in shared-socioeconomic pathways (SSP) and representative concentration pathways (RCP) between 2070 an 2100 based on synthetic tracks produced with 7 climate models (with bias correction) over 250 representative years launched independently. Top range: $95 \%$ - 99\% (extremely unlikely losses), followed by $95 \%-66 \%, 50 \%-66 \%$ and $0 \%-50 \%$. Historical damages are computed with 300 representative years of synthetic tracks generated with ERA-5 between 1980-2010. The physical asset value is corrected by inflation between cyclone year and 2014 (GDP ref. year of Litpop).
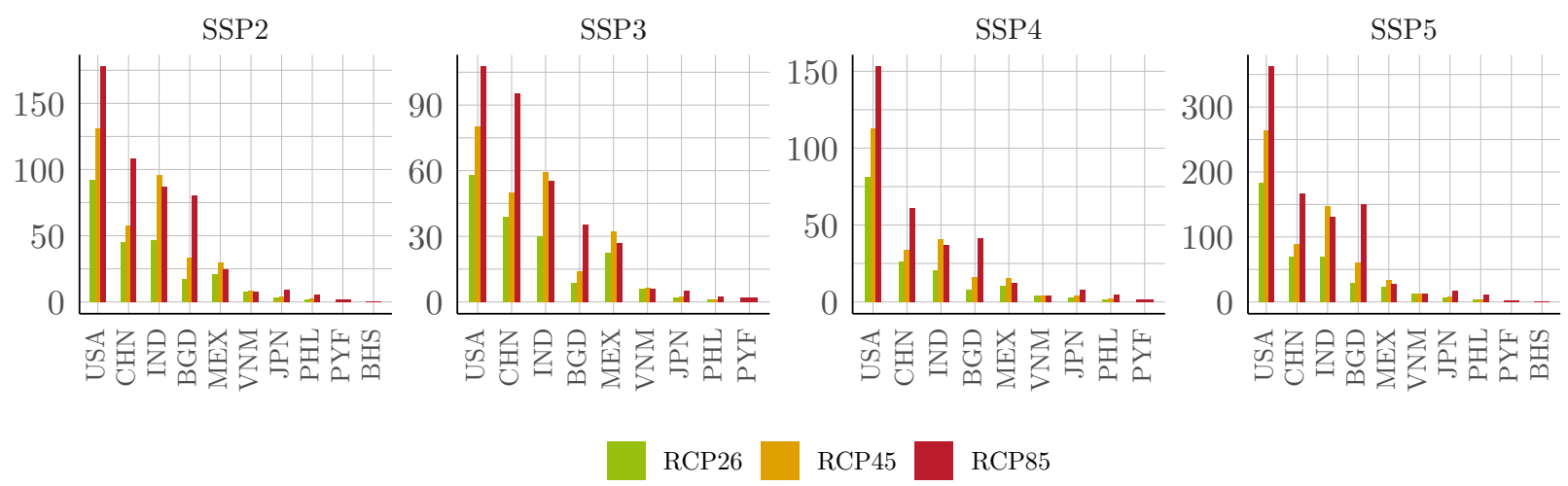

Figure 20. Annualized regional damage in SSP and RCP between 2070 an 2100 based on synthetic tracks produced with 7 climate models (with bias correction) over 250 representative years launched independently. The scale differs between SSPs.

ciated to the socio-economic pathway SSP2 (i.e. the "Middle of the Road" scenario in O'Neill et al. (2014)'s framework). The choice of the socio-economic scenario is also determinant for damage estimation. In the case of the SSP5 socio-economic scenario (which assumes sustained exponential economic growth), with constant damage functions, the previous figures become 120\%, 203\% and 306\% respectively. Figure 19 provides the quantile values for the modeled damage obtained using CATHERINA. At a global scale, in the SSP2 and the RCP 4.5 damages above USD 67.7 billion are more likely than not, accounting 
https://doi.org/10.5194/gmd-2021-384

Preprint. Discussion started: 2 December 2021

(c) Author(s) 2021. CC BY 4.0 License.

(c) (i)

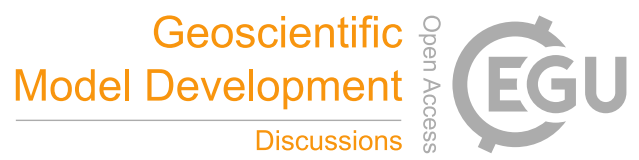

for direct damage only. Figures 20 displays the average annual damage per country, in the different shared-socioeconomic pathways.

\section{Conclusions}

390 This paper proposes a relatively simple structural framework to generate synthetic storms based on large-scale climate data. We show that when used with reanalysis data and CMIP5 models, our method produces tracks consistent with historical observations.

The synthetic tracks generated with our model have several applications. The first one is in natural disaster risk management, to calibrate adaptation measures. For this purpose, the track generation algorithm may be enhanced, for instance, by including dependency in the latitudinal and longitudinal incremental displacement, coupling with a meteorological forecasting model, or including ground topography to model the cyclone displacement over land. Another major field of application is to climate financial risk management, where this scenario-based events database can be used to evaluate physical risks and compute portfolio exposures. This would require to better define asset-level vulnerabilities.

Code and data availability. Code is available from the E4C datahub at https://www.e4c.ip-paris.fr/\#/fr/datahub/projects, and Zenodo at 10. 5281/zenodo.5645516. The deposit includes R scripts with functions, a fitting script, the parameters of the fitting of all the relationships on ERA-5, historical and future synthetic tracks, and a sample of simulated annual damage per country and scenario. We included a user guide for data exploration and a quick start guide. 


\section{References}

Aznar Siguan, G. and Bresch, D. N.: CLIMADA v1: a global weather and climate risk assessment platform, Geoscientific Model Development, 12, 3085-3097, 2019.

Bloemendaal, N., Haigh, I. D., de Moel, H., Muis, S., Haarsma, R. J., and Aerts, J. C.: Generation of a global synthetic tropical cyclone hazard dataset using STORM, Scientific Data, 7, 1-12, 2020.

Bresch, D. N.: CLIMADA-the open-source and-access global probabilistic risk modelling platform, 2017.

Butchart, N., Austin, J., Knight, J. R., Scaife, A. A., and Gallani, M. L.: The response of the stratospheric climate to projected changes in the concentrations of well-mixed greenhouse gases from 1992 to 2051, Journal of climate, 13, 2142-2159, 2000.

Center for International Earth Science Information Network (CIESIN): Documentation for the gridded population of the world, Version 4 (GPWv4), Revision 10 Data Sets, 2017.

Chen, G., Li, X., Liu, X., Chen, Y., Liang, X., Leng, J., Xu, X., Liao, W., Wu, Q., Huang, K., et al.: Global projections of future urban land expansion under shared socioeconomic pathways, Nature communications, 11, 1-12, 2020.

DeMaria, M. and Kaplan, J.: A statistical hurricane intensity prediction scheme (SHIPS) for the Atlantic basin, Weather and Forecasting, 9, 209-220, 1994.

DeMaria, M., Knaff, J. A., and Connell, B. H.: A tropical cyclone genesis parameter for the tropical Atlantic, Weather and Forecasting, 16, 219-233, 2001.

Eberenz, S., Stocker, D., Röösli, T., and Bresch, D. N.: LitPop: Global Exposure Data for Disaster Risk Assessment, 2019.

Eberenz, S., Lüthi, S., and Bresch, D. N.: Regional tropical cyclone impact functions for globally consistent risk assessments, Natural Hazards and Earth System Sciences Discussions, pp. 1-29, 2020a.

Eberenz, S., Stocker, D., Röösli, T., and Bresch, D. N.: Asset exposure data for global physical risk assessment, Earth Syst, 12, https: //doi.org/10.5194/essd-12-817-2020, 2020b.

Emanuel, K., Sundararajan, R., and Williams, J.: Hurricanes and global warming: Results from downscaling IPCC AR4 simulations, Bulletin of the American Meteorological Society, 89, 347-368, 2008.

Emanuel, K. A.: The maximum intensity of hurricanes, Journal of the Atmospheric Sciences, 45, 1143-1155, 1988.

Emanuel, K. A.: The theory of hurricanes, Annual Review of Fluid Mechanics, 23, 179-196, 1991.

Emanuel, K. A.: Thermodynamic control of hurricane intensity, Nature, 401, 665-669, 1999.

Emanuel, K. A.: Increasing destructiveness of tropical cyclones over the past 30 years, Nature, 436, 686-688, 2005.

Emanuel, K. A.: Global warming effects on US hurricane damage, Weather, Climate, and Society, 3, 261-268, 2011.

Fabregat, A., Mezic, I., and Poje, A. C.: Finite-time partitions for lagrangian structure identification in Gulf Stream eddy transport, arXiv preprint arXiv:1606.07382, 2016.

Forster, P. M., Bodeker, G., Schofield, R., Solomon, S., and Thompson, D.: Effects of ozone cooling in the tropical lower stratosphere and upper troposphere, Geophysical Research Letters, 34, 2007.

Gray, W. M.: Tropical cyclone genesis, Atmospheric science paper; no. 234, 1975.

Guha-Sapir, D., Below, R., and Hoyois, P.: EM-DAT: the CRED/OFDA international disaster database, 2018.

Gusain, A., Ghosh, S., and Karmakar, S.: Added value of CMIP6 over CMIP5 models in simulating Indian summer monsoon rainfall, Atmospheric Research, 232, 104 680, 2020. 
https://doi.org/10.5194/gmd-2021-384

Preprint. Discussion started: 2 December 2021

(c) Author(s) 2021. CC BY 4.0 License.

(c) (i)

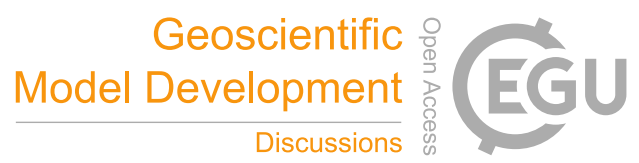

Hall, T. M. and Jewson, S.: Statistical modelling of North Atlantic tropical cyclone tracks, Tellus A: Dynamic Meteorology and Oceanography, 59, 486-498, 2007.

Holland, G. J.: The maximum potential intensity of tropical cyclones, Journal of the atmospheric sciences, 54, 2519-2541, 1997.

James, M. and Mason, L.: Synthetic tropical cyclone database, Journal of waterway, port, coastal, and ocean engineering, 131, 181-192, 2005.

James, M. and Mason, L.: Closure to "Synthetic Tropical Cyclone Database" by MK James and LB Mason, Journal of Waterway, Port, Coastal, and Ocean Engineering, 132, 502-503, 2006.

Jien, J. Y., Gough, W. A., Butler, K., Cheng, V., and Arhonditsis, G.: Near-Time Sea Surface Temperature and Tropical Cyclone Intensity in the Eastern North Pacific Basin, in: Hurricanes and Climate Change, pp. 55-89, Springer, 2017.

Jones, B. and O’Neill, B. C.: Global One-Eighth Degree Population Base Year and Projection Grids Based on the Shared Socioeconomic Pathways, Palisades, 2020 .

Kaplan, J. and DeMaria, M.: A simple empirical model for predicting the decay of tropical cyclone winds after landfall, Journal of applied meteorology, 34, 2499-2512, 1995.

Knapp, K. R., Kruk, M. C., Levinson, D. H., Diamond, H. J., and Neumann, C. J.: The international best track archive for climate stewardship (IBTrACS) unifying tropical cyclone data, Bulletin of the American Meteorological Society, 91, 363-376, 2010.

Lüthi, S.: Applying Machine Learning Methods to the Assessment of Tropical Cyclone Impacts, Master thesis, ETH Zurich, 2019.

Mendelsohn, R., Emanuel, K., Chonabayashi, S., and Bakkensen, L.: The impact of climate change on global tropical cyclone damage, Nature climate change, 2, 205-209, 2012.

Merrill, R. T.: An experiment in statistical prediction of tropical cyclone intensity change, vol. 34, US Department of Commerce, National Oceanic and Atmospheric Administration, 1987.

Michelangeli, P.-A., Vrac, M., and Loukos, H.: Probabilistic downscaling approaches: Application to wind cumulative distribution functions, Geophysical Research Letters, 36, 2009.

Neu, U., Akperov, M. G., Bellenbaum, N., Benestad, R., Blender, R., Caballero, R., Cocozza, A., Dacre, H. F., Feng, Y., Fraedrich, K., et al.: IMILAST: A community effort to intercompare extratropical cyclone detection and tracking algorithms, Bulletin of the American Meteorological Society, 94, 529-547, 2013.

O’Neill, B. C., Kriegler, E., Riahi, K., Ebi, K. L., Hallegatte, S., Carter, T. R., Mathur, R., and van Vuuren, D. P.: A new scenario framework for climate change research: the concept of shared socioeconomic pathways, Climatic change, 122, 387-400, 2014.

O’Neill, B. C., Kriegler, E., Ebi, K. L., Kemp-Benedict, E., Riahi, K., Rothman, D. S., van Ruijven, B. J., van Vuuren, D. P., Birkmann, J., Kok, K., et al.: The roads ahead: Narratives for shared socioeconomic pathways describing world futures in the 21 st century, Global environmental change, 42, 169-180, 2017.

Pachauri, R. K., Allen, M. R., Barros, V. R., Broome, J., Cramer, W., Christ, R., Church, J. A., Clarke, L., Dahe, Q., Dasgupta, P., et al.: Climate change 2014: synthesis report. Contribution of Working Groups I, II and III to the fifth assessment report of the Intergovernmental Panel on Climate Change, Ipcc, 2014.

Prahl, B. F., Rybski, D., Burghoff, O., and Kropp, J. P.: Comparison of storm damage functions and their performance, Nat. Hazards Earth Syst. Sci., 15, 769-788, 2015.

Ramaswamy, V., Schwarzkopf, M., Randel, W., Santer, B., Soden, B. J., and Stenchikov, G.: Anthropogenic and natural influences in the evolution of lower stratospheric cooling, Science, 311, 1138-1141, 2006. 
https://doi.org/10.5194/gmd-2021-384

Preprint. Discussion started: 2 December 2021

(c) Author(s) 2021. CC BY 4.0 License.

(c) (1)

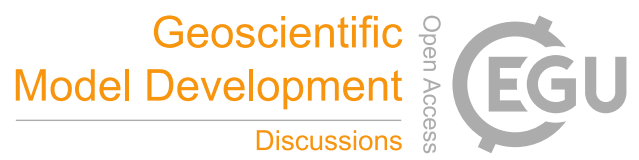

Román, M. O., Wang, Z., Sun, Q., Kalb, V., Miller, S. D., Molthan, A., Schultz, L., Bell, J., Stokes, E. C., Pandey, B., et al.: NASA’s Black Marble nighttime lights product suite, Remote Sensing of Environment, 210, 113-143, 2018.

Sherwood, S. C., Ingram, W., Tsushima, Y., Satoh, M., Roberts, M., Vidale, P. L., and O'Gorman, P. A.: Relative humidity changes in a warmer climate, Journal of Geophysical Research: Atmospheres, 115, 2010.

480 Solomon, S., Manning, M., Marquis, M., Qin, D., et al.: Climate change 2007-the physical science basis: Working group I contribution to the fourth assessment report of the IPCC, vol. 4, Cambridge university press, 2007.

Taylor, K. E., Stouffer, R. J., and Meehl, G. A.: An overview of CMIP5 and the experiment design, Bulletin of the American meteorological Society, 93, 485-498, 2012.

Unanwa, C., McDonald, J., Mehta, K., and Smith, D.: The development of wind damage bands for buildings, Journal of Wind Engineering and Industrial Aerodynamics, 84, 119-149, 2000.

Vrac, M., Drobinski, P., Merlo, A., Herrmann, M., Lavaysse, C., Li, L., and Somot, S.: Dynamical and statistical downscaling of the French Mediterranean climate: uncertainty assessment, Natural Hazards and Earth System Sciences, 12, 2769-2784, 2012.

World Bank: Building the World Bank's Wealth Accounts: Methods and Data, https://development-data-hub-s3-public.s3.amazonaws.com/ ddhfiles/94641/wealth-methodology-january-30-2018_4_0.pdf, 2018.

Acknowledgements. This work contributes to the Energy4Climate Interdisciplinary Center (E4C) of Institut Polytechnique de Paris and Ecole des Ponts ParisTech, supported by 3rd Programme d'Investissements d'Avenir [ANR-18-EUR-0006-02]. Peter Tankov gratefully acknowledges financial support from the FIME Research Initiative. The authors are very grateful to Florian Raymond, Thierry Roncalli, Takaya Sekine and Lauren Stagnol for helpful comments. 


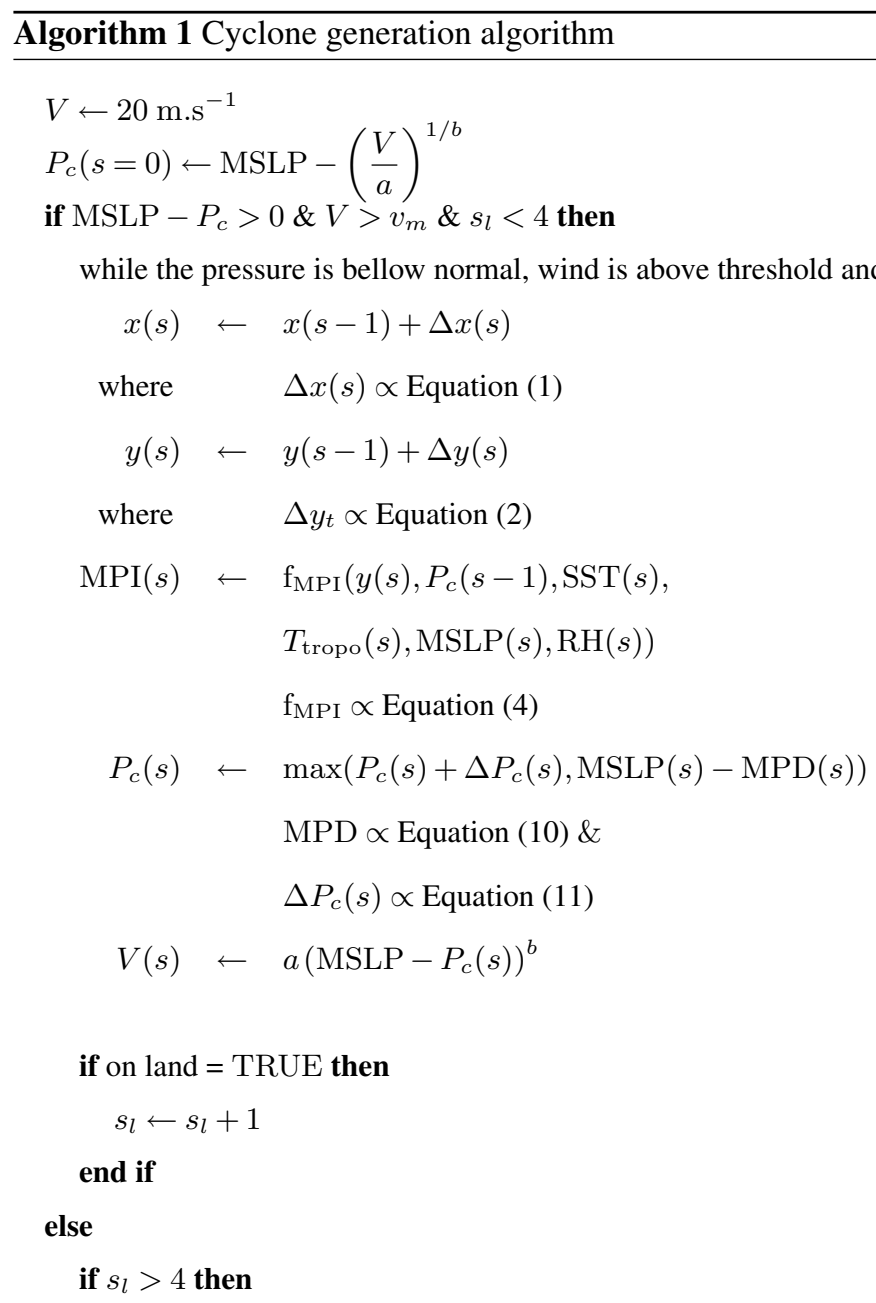

Same functional for $x$ and $y$ but, compute distance to land $D(s)$ from natural earth coastlines and do

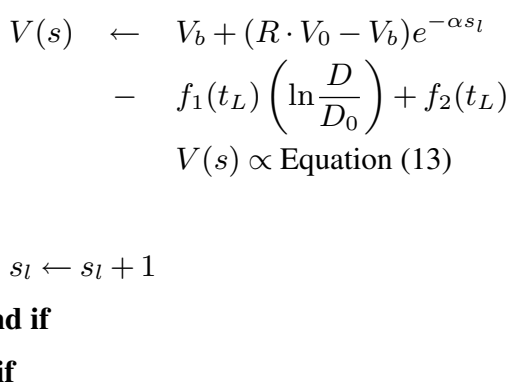

Note: This algorithm assumes step-wise extraction of climate data in the Monte-Carlo process. Another way, closer to the framework suggested in Bloemendaal et al. (2020) would be to (i) compute the tracks without properties, (ii) retrieve all climate variables, (iii) determine the properties using the extracted climate conditions in the last step. 
Nature

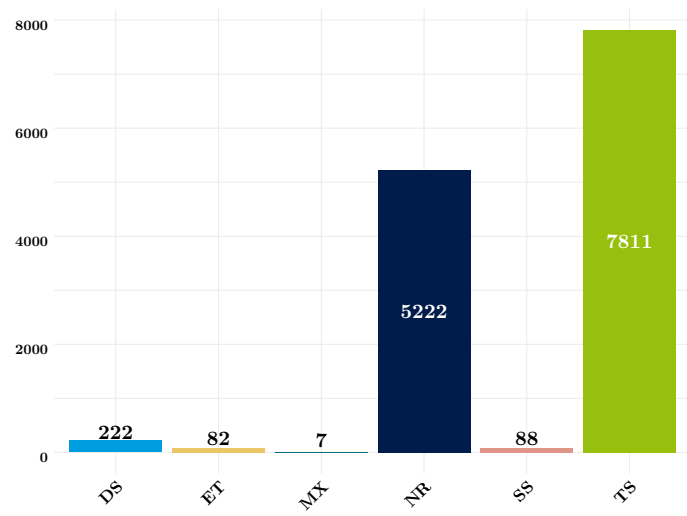

Agency

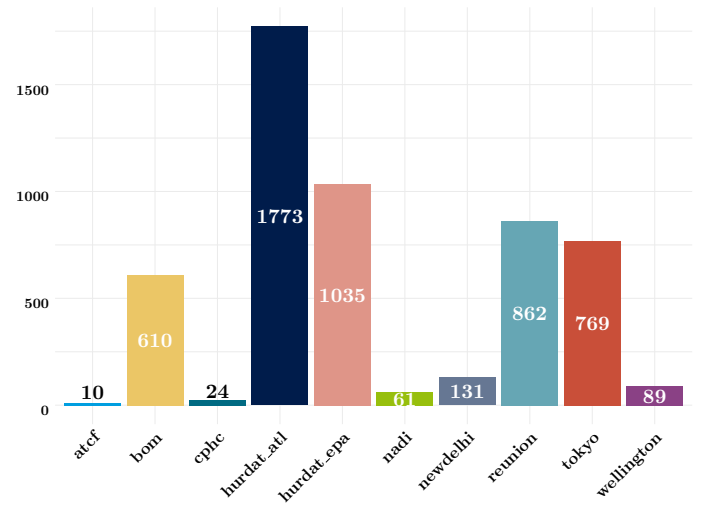

Basin

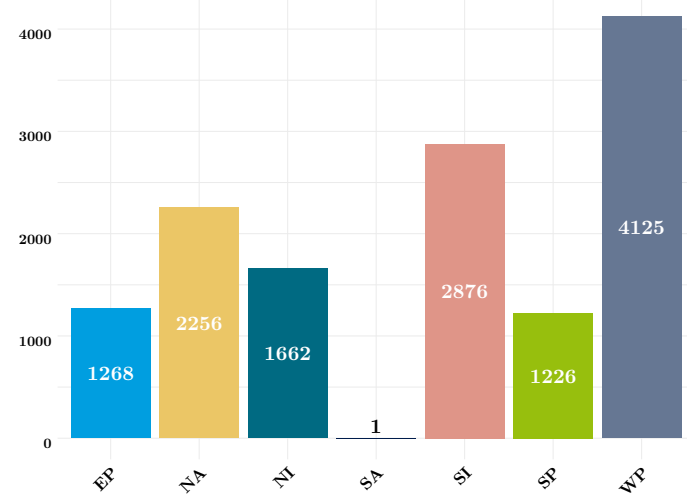

Sub-basin

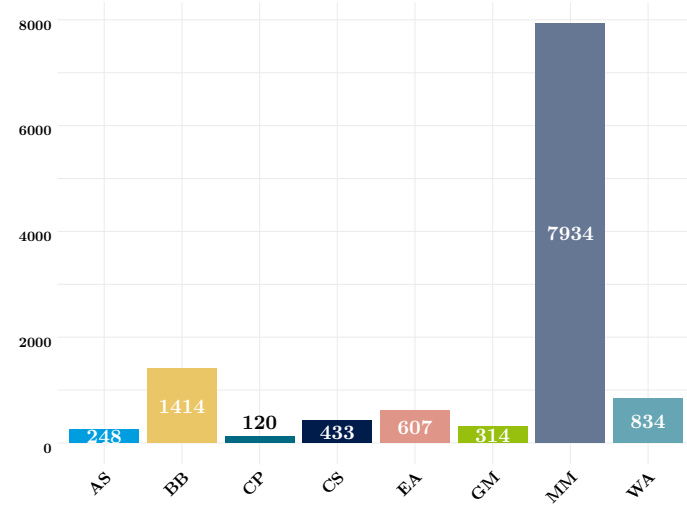

Figure A1. Information in IBTrACS.The cyclones are split by nature (DS: Disturbance; TS: Tropical; TE: Extratropical; ST: Subtropical; NR: Not reported; MX: Mixture or contradicting nature reports from different agencies). We remove Extratropical cyclones (75) and Disturbance (205). The cyclones are reported in the following basins: East Pacific (EP); North America (NA); North India (NI); South America (SA); South India (SI); South Pacific (SP); Western Pacific (WP). One can also explore sub-basin decomposition Eberenz et al. (2020a) (MM : missing - no sub basin for this basin (no sub-basins provided for WP, SI); CS : Caribbean Sea; GM : Gulf of Mexico; CP : Central Pacific; BB : Bay of Bengal; AS : Arabian Sea; WA : Western Australia; EA : Eastern Australia) but we chose to use basins. The different agencies worldwide report central pressure and maximum wind speed but use sometimes different standards. In particular, the reporting can vary in terms of sustained wind speed. According to the dataset documentation the North Atlantic - U.S. Miami (NOAA NHC) bureau (hurdat/atcf) gives the 1-minute winds speed while Tokyo i.e. RSMC Tokyo (JMA) provides dirrectly the 10-minute sustained wind speed (Similarly, newdelhi corresponding to RSMC New Delhi (IMD) gives the 3-minute wind speed; reunion - RSMC La Reunion (MFLR), the Australian TCWCs (TCWC Perth, Darwin, Brisbane) (BOM), the RSMC Nadi (FMS); TCWC Wellington (NZMS) provide the 10 minute sustained wind speed and (CMA) 2-minute sustained wind). The lack of reporting standards between agencies is a source of uncertainty in the input data. 


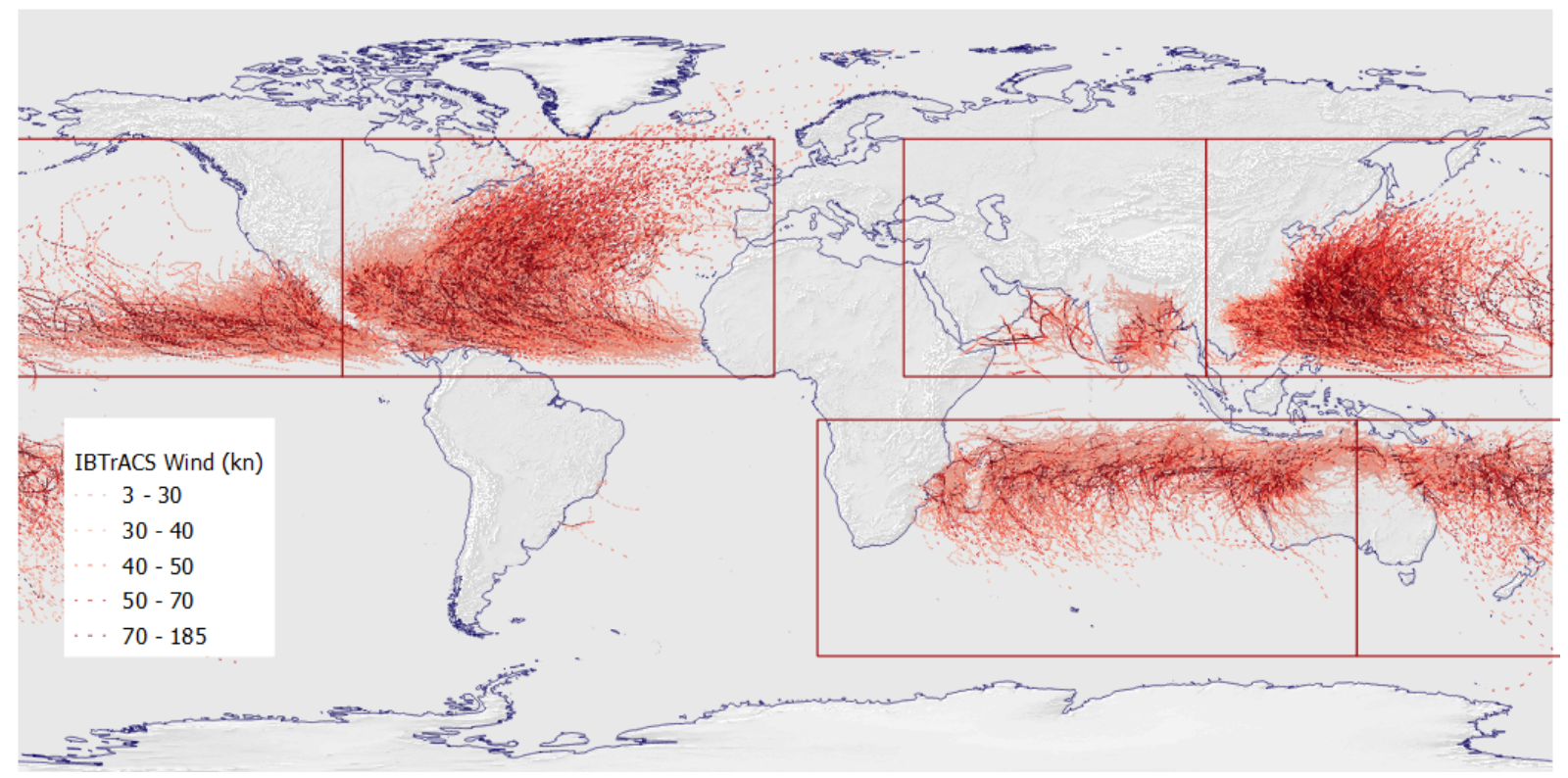

Figure A2. IBTrACS full database tracks 
https://doi.org/10.5194/gmd-2021-384

Preprint. Discussion started: 2 December 2021

(c) Author(s) 2021. CC BY 4.0 License.

(c) (i)

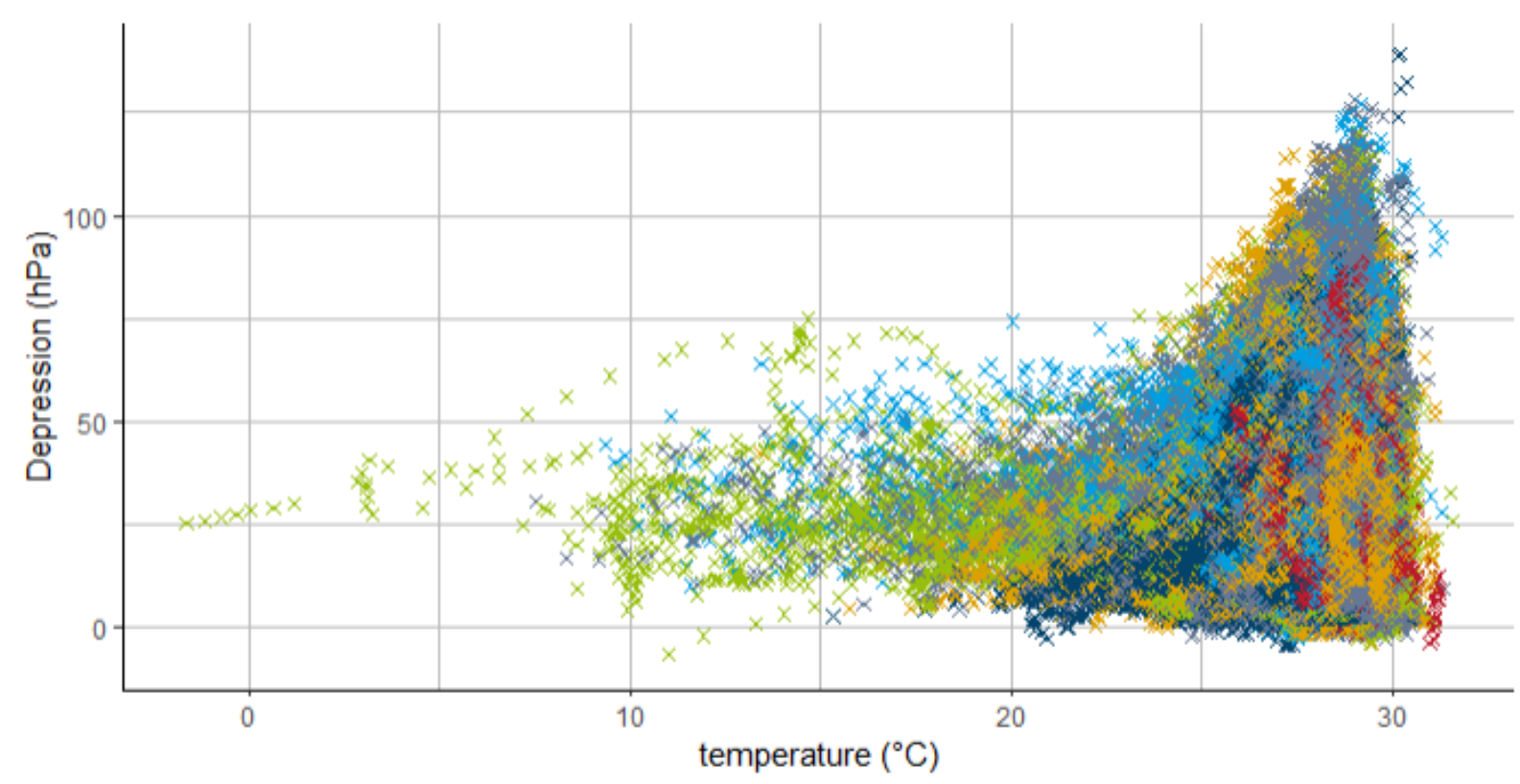

$\times \mathrm{EP} \times \mathrm{NI} \times \mathrm{SP}$
$\times \mathrm{NA} \times \mathrm{SI} \times \mathrm{WP}$

Figure A3. Depression and sea surface temperature 


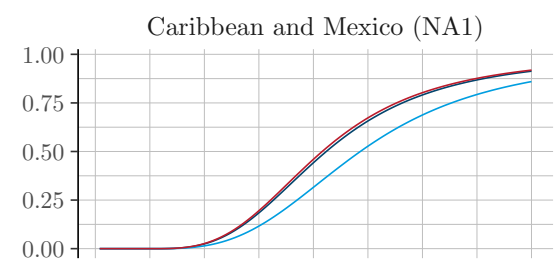

Oceania (OC)

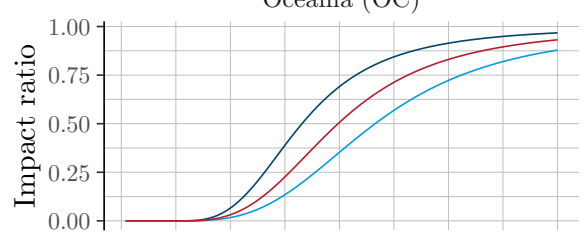

Pilippines (WP2)
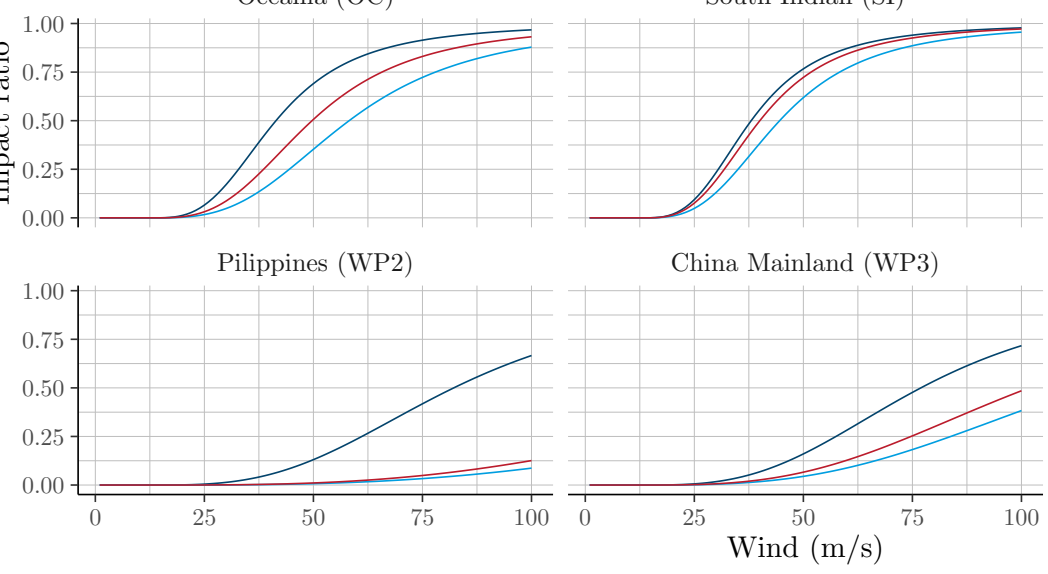

China Mainland (WP3)

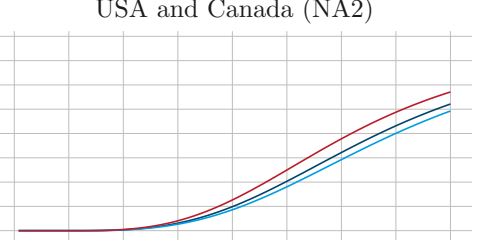

South Indian (SI)

— RMSF — TDR1.0 - TDR1.5
North Indian (NI)

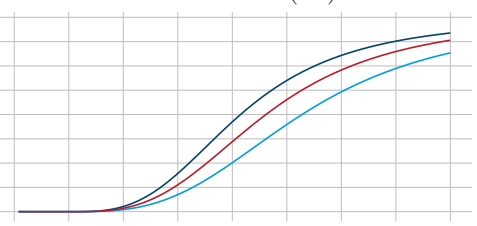

South East Asia (WP1)

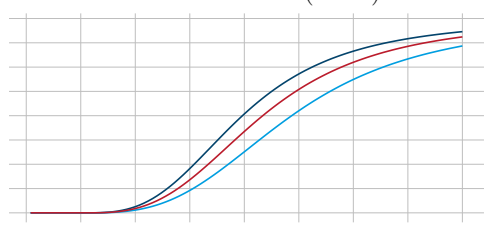

North West Pacific (WP4)

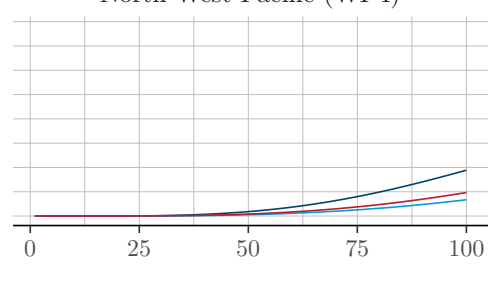

Figure A4. Regional Optimal Damage Functions of the CLIMADA package (Eberenz et al., 2020a) 
https://doi.org/10.5194/gmd-2021-384

Preprint. Discussion started: 2 December 2021

(c) Author(s) 2021. CC BY 4.0 License.

(c) (1)
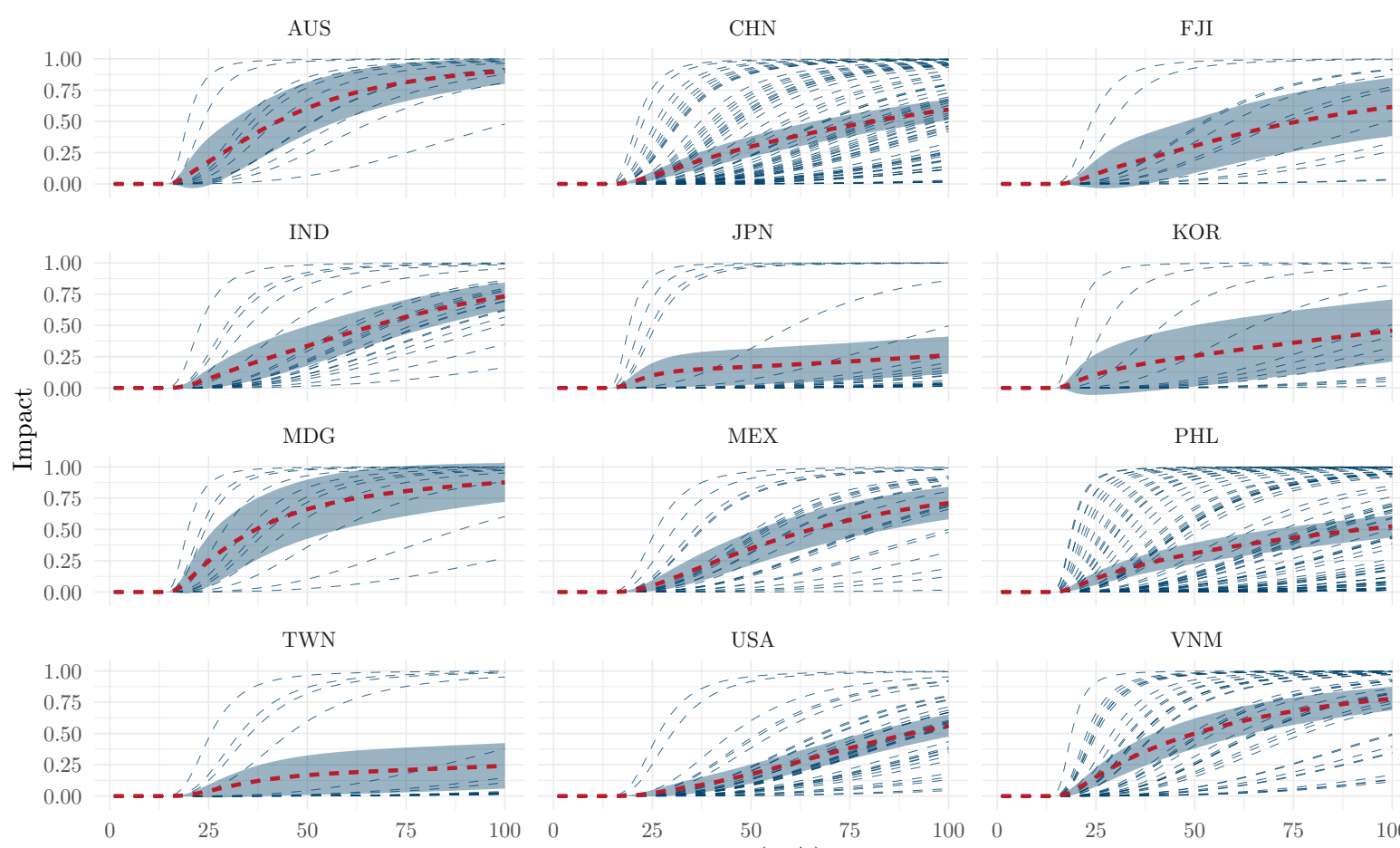

JPN
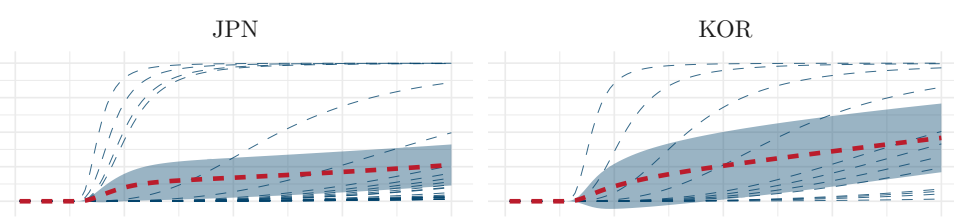

MEX

PHL

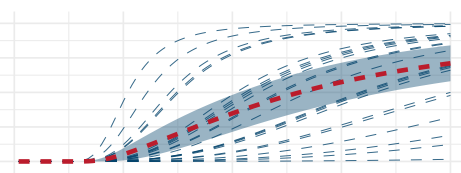

USA
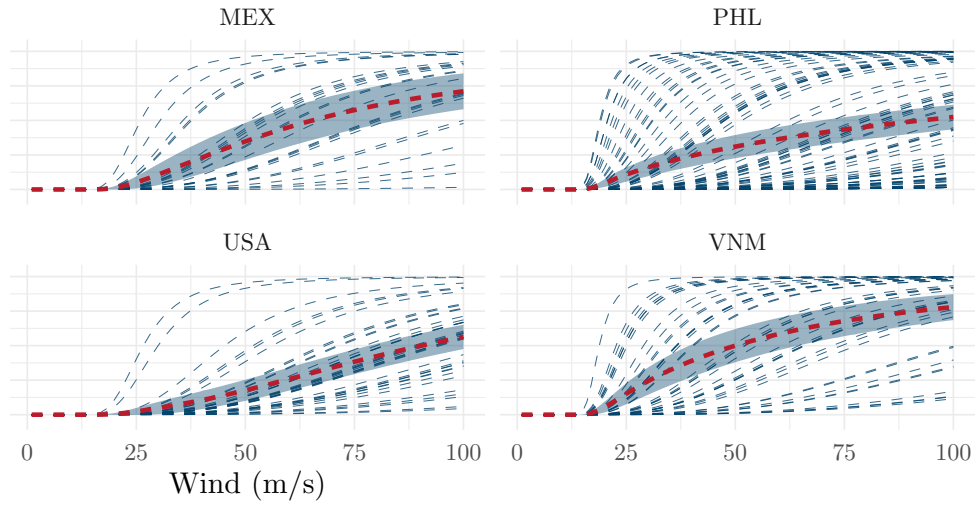

Figure A5. Country calibration of damage function (when the countries has been hit more than 5 times) 

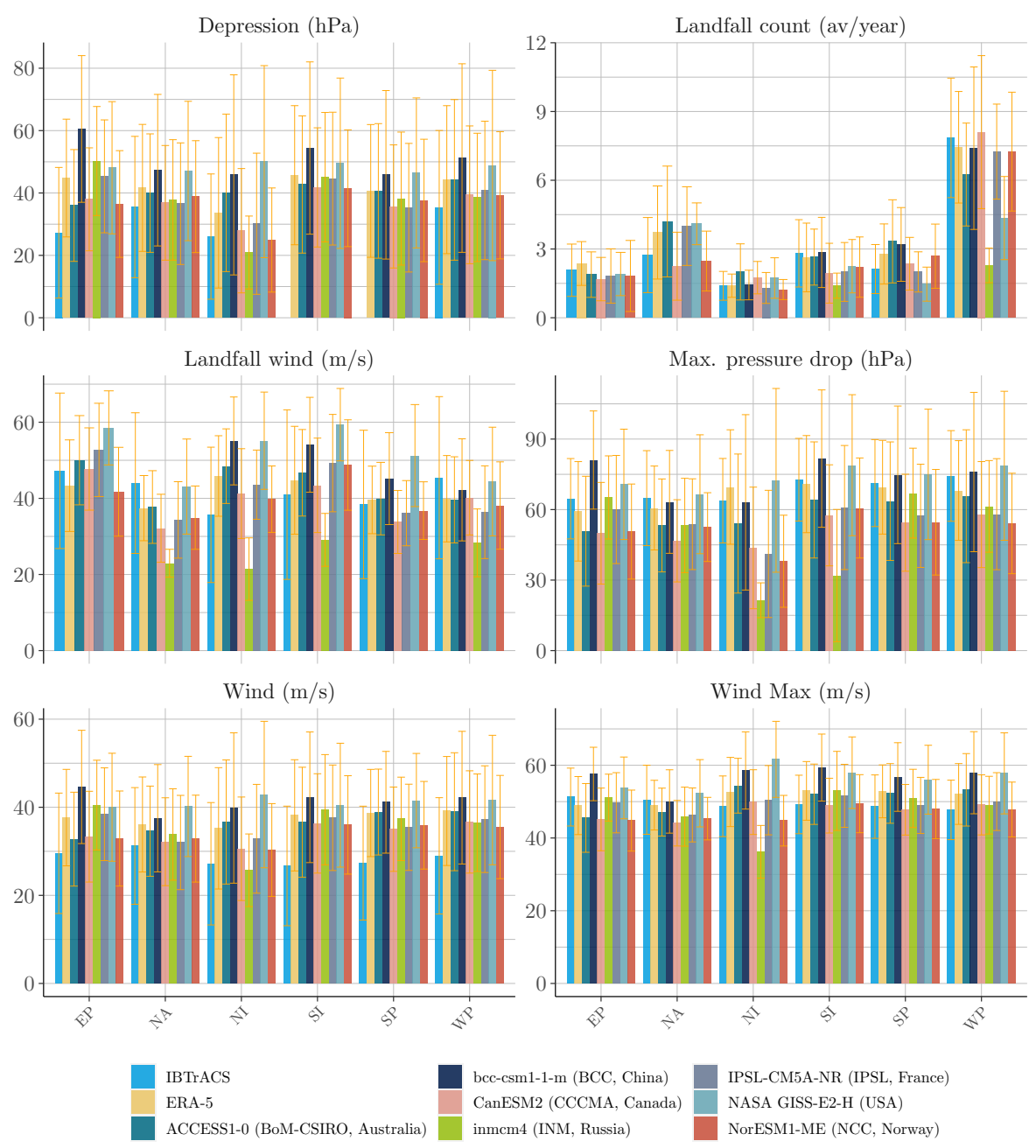

Figure A6. Evidence of models uncertainty. A comparison of the properties obtained generating 30 years of tropical cyclones with different models from the CMIP5 raw climate data versus ERA-5. The average number of cyclone making landfall is computed averaging the number of event with a number of steps on land positive $\left(s_{l}>0\right)$. Maximum pressure drop and wind are respectively computed extracting the maximum value for the corresponding variables of the cyclone tracks. The light blue bars represent the mean of the variable of interest among IBTrACS filtered dataset (with the confidence interval drawn from the standard deviation of the distribution). The yellow bars represent the same variable extracted from the synthetic data generated by the algorithm 1 using ERA-5 data. In terms of average values the models produce consistent tracks on every basins. Then, we compare the output of this algorithm with different climate data produced on the historical by the climate models taking part of the $5^{t h}$ phase of the CMIP. A general observation is the poorer performance of the model in the North Indian basin. This could be due to the smaller number of intense cyclones remaining in the sample after the filtration by intensity (1.6 storms per year with wind exceeding $35 \mathrm{~m} \cdot \mathrm{s}^{-1}$ ). 

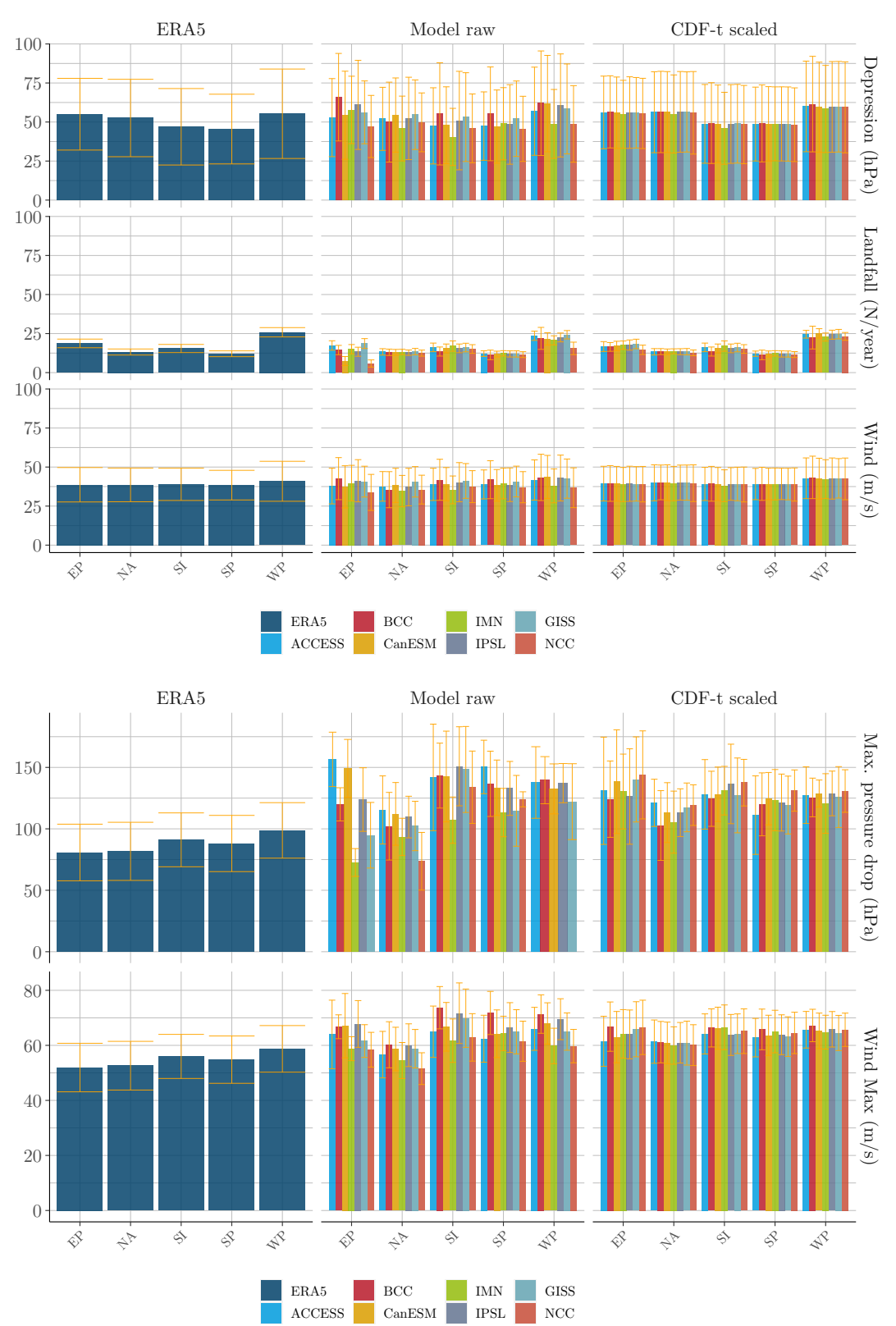

Figure A7. Bias correction (300 years with ERA-5). On the top grid, we compare Depression (hPa), landfall count and winds, on the full sample. We can see that the correction effectively centers the distribution of ERA-5 properties. The grid bellow focuses on a grouping on maximum wind and depressions. We note that the correction also allows us to reduce the dispersion between models, however, it tends to shift up extreme values. 

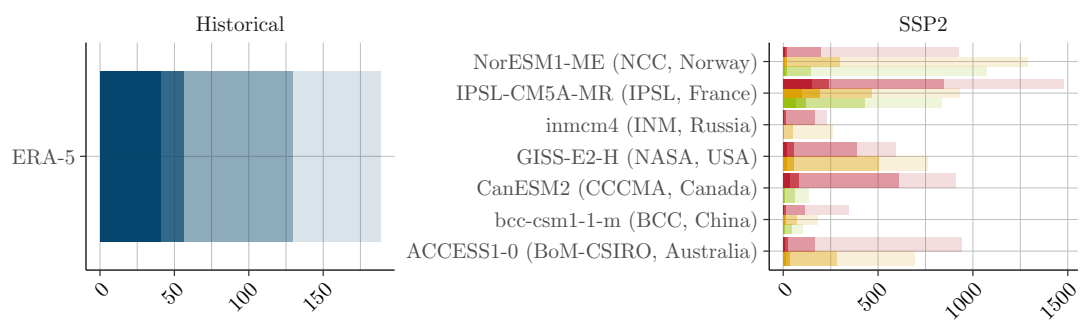

SSP3
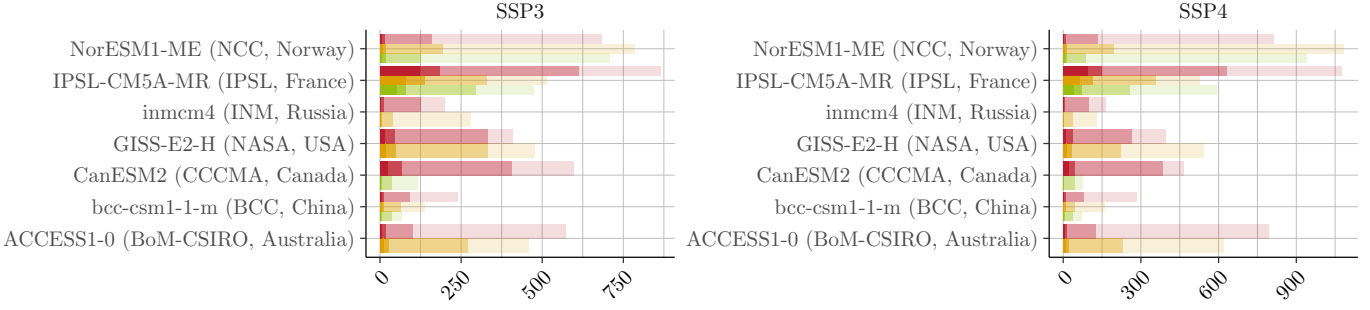

SSP5

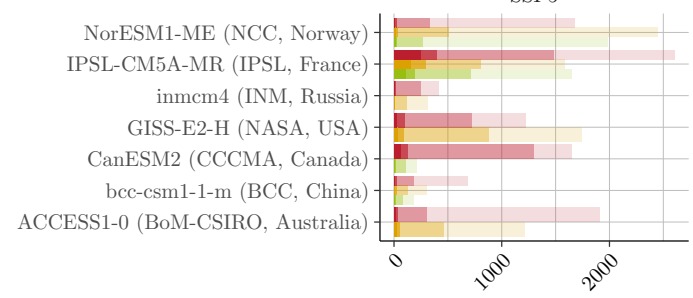

Historical

RCP26

$\mathrm{RCP} 45$

RCP 85

Figure A8. Simulated damage quantiles distributions per model per scenario (historical is restricted to ERA- for visualisation purpose). 0-50percentiles, 50-66 percentiles 66-95 and 95 to 99 percentiles are represented. 
https://doi.org/10.5194/gmd-2021-384

Preprint. Discussion started: 2 December 2021

(c) Author(s) 2021. CC BY 4.0 License.

Table A1. EM-DAT reporting proportions ${ }^{\star}$

\begin{tabular}{|c|c|c|c|c|c|}
\hline & Total Damages (US\$) & Total Deaths & Insured (US\$) & Total Affected & Recnst. Costs ${ }^{\star \star}$ (US\$) \\
\hline Ash fall & $0,12 \%$ & $1,09 \%$ & $0,00 \%$ & $0,09 \%$ & $0,00 \%$ \\
\hline Avalanche & $0,02 \%$ & $0,20 \%$ & $0,02 \%$ & $0,00 \%$ & $0,00 \%$ \\
\hline Coastal flood & $0,30 \%$ & $0,14 \%$ & $0,14 \%$ & $0,32 \%$ & $0,00 \%$ \\
\hline Cold wave & $0,37 \%$ & $0,70 \%$ & $0,51 \%$ & $0,25 \%$ & $0,00 \%$ \\
\hline Convective storm & $9,86 \%$ & $0,68 \%$ & $21,78 \%$ & $4,51 \%$ & $0,00 \%$ \\
\hline Drought & $5,29 \%$ & $24,75 \%$ & $2,58 \%$ & $36,35 \%$ & $0,00 \%$ \\
\hline Extra-tropical storm & $1,60 \%$ & $0,02 \%$ & $3,09 \%$ & $0,06 \%$ & $3,31 \%$ \\
\hline Flash flood & $2,07 \%$ & $2,58 \%$ & $1,18 \%$ & $3,03 \%$ & $0,00 \%$ \\
\hline Forest fire & $2,45 \%$ & $0,08 \%$ & $3,86 \%$ & $0,09 \%$ & $0,76 \%$ \\
\hline Ground movement & $16,75 \%$ & $26,78 \%$ & $6,59 \%$ & $2,61 \%$ & $87,07 \%$ \\
\hline Heat wave & $0,68 \%$ & $7,09 \%$ & $0,03 \%$ & $0,08 \%$ & $0,00 \%$ \\
\hline Land fire ${ }^{\star \star \star}$ & $0,80 \%$ & $0,03 \%$ & $1,76 \%$ & $0,02 \%$ & $0,00 \%$ \\
\hline Landslide & $0,14 \%$ & $1,04 \%$ & $0,01 \%$ & $0,15 \%$ & $0,00 \%$ \\
\hline Lava flow & $0,02 \%$ & $0,00 \%$ & $0,00 \%$ & $0,01 \%$ & $0,00 \%$ \\
\hline Mudslide & $0,10 \%$ & $0,21 \%$ & $0,00 \%$ & $0,02 \%$ & $0,00 \%$ \\
\hline Pyroclastic flow & $0,01 \%$ & $0,02 \%$ & $0,00 \%$ & $0,03 \%$ & $0,00 \%$ \\
\hline Riverine flood & $16,61 \%$ & $5,20 \%$ & $6,59 \%$ & $38,68 \%$ & $4,46 \%$ \\
\hline Rockfall & $0,00 \%$ & $0,02 \%$ & $0,00 \%$ & $0,00 \%$ & $0,00 \%$ \\
\hline Severe winter cond. & $0,74 \%$ & $0,16 \%$ & $0,20 \%$ & $1,27 \%$ & $0,00 \%$ \\
\hline Subsidence & $0,00 \%$ & $0,01 \%$ & $0,00 \%$ & $0,00 \%$ & $0,00 \%$ \\
\hline Tropical cyclone & $34,26 \%$ & $18,33 \%$ & $45,64 \%$ & $12,34 \%$ & $2,23 \%$ \\
\hline Tsunami & $7,81 \%$ & $10,87 \%$ & $6,01 \%$ & $0,11 \%$ & $2,16 \%$ \\
\hline
\end{tabular}

Notes:

* Proportion exclude damages which sub types are not reported.

${ }^{\star \star}$ Reconstruction costs are not well reported over disaster subtypes.

$\star \star \star$ Brush, Bush, Pasture

Among disasters subtypes, tropical cyclones present an higher quality in reporting and represent a large share of total damages. 
https://doi.org/10.5194/gmd-2021-384

Preprint. Discussion started: 2 December 2021

(c) Author(s) 2021. CC BY 4.0 License.

Table A2. Latitude displacement fitting parameters (Equation (2))

\begin{tabular}{lllllr}
\hline BASIN & term & estimate & \multicolumn{1}{c}{ std.error } & \multicolumn{1}{l}{ statistic } & \multicolumn{1}{r}{ p.value } \\
\hline EP & $b_{0}$ & 0,018279 & 0,000578 & 31,61335 & $1,8 \mathrm{E}-217$ \\
EP & $b_{1}$ & 0,921913 & 0,001299 & 709,8495 & 0 \\
EP & $b_{2}$ & $-0,11173$ & 0,007173 & $-15,5768$ & $1,36 \mathrm{E}-54$ \\
NA & $b_{0}$ & 0,039692 & 0,000893 & 44,46119 & 0 \\
NA & $b_{1}$ & 0,925234 & 0,000875 & 1057,432 & 0 \\
NA & $b_{2}$ & $-0,54769$ & 0,017301 & $-31,6563$ & $5,4 \mathrm{E}-219$ \\
NI & $b_{0}$ & 0,025484 & 0,000829 & 30,73553 & $1,4 \mathrm{E}-205$ \\
NI & $b_{1}$ & 0,884275 & 0,001987 & 445,0171 & 0 \\
NI & $b_{2}$ & $-0,13652$ & 0,010223 & $-13,3543$ & $1,31 \mathrm{E}-40$ \\
SI & $b_{0}$ & $-0,03668$ & 0,000614 & $-59,7483$ & 0 \\
SI & $b_{1}$ & 0,904971 & 0,000964 & 938,7951 & 0 \\
SI & $b_{2}$ & $-0,32366$ & 0,007824 & $-41,365$ & 0 \\
SP & $b_{0}$ & $-0,06065$ & 0,001493 & $-40,6141$ & 0 \\
SP & $b_{1}$ & 0,890401 & 0,0016 & 556,4426 & 0 \\
SP & $b_{2}$ & $-0,69044$ & 0,02201 & $-31,3691$ & $2,3 \mathrm{E}-214$ \\
WP & $b_{0}$ & 0,035608 & 0,000517 & 68,81579 & 0 \\
WP & $b_{1}$ & 0,915577 & 0,000777 & 1178,712 & 0 \\
WP & $b_{2}$ & $-0,27391$ & 0,006231 & $-43,9559$ & 0 \\
\hline & & & & &
\end{tabular}

Table A3. Latitude displacement model performance

\begin{tabular}{lrrrrrl}
\hline BASIN & r.squared & adj.r.squared & \multicolumn{1}{l}{ sigma } & \multicolumn{1}{l}{ logLik } & \multicolumn{1}{l}{ AIC } & \multicolumn{1}{l}{ BIC } \\
\hline EP & 0,90043 & 0,900426 & 0,063665 & 76272,6 & -152537 & -152501 \\
NA & 0,917525 & 0,917524 & 0,09362 & 109496,4 & -218985 & -218946 \\
NI & 0,797487 & 0,797479 & 0,076285 & 59200,61 & -118393 & -118358 \\
SI & 0,866233 & 0,866231 & 0,07854 & 171310,6 & -342613 & -342573 \\
SP & 0,850892 & 0,850887 & 0,114029 & 47915,78 & $-95823,6$ & $-95787,3$ \\
WP & 0,872193 & 0,872192 & 0,107743 & 181021 & -362034 & -361993 \\
\hline
\end{tabular}


https://doi.org/10.5194/gmd-2021-384

Preprint. Discussion started: 2 December 2021

(c) Author(s) 2021. CC BY 4.0 License.

Table A4. Longitude displacement fitting parameters (Equation (1))

\begin{tabular}{lllllr}
\hline BASIN & term & estimate & std.error & statistic & \multicolumn{1}{l}{ p.value } \\
\hline EP & $a_{0}$ & $-0,00295$ & 0,000537 & $-5,48697$ & $4,11 \mathrm{E}-08$ \\
EP & $a_{1}$ & 0,982384 & 0,001048 & 937,3607 & 0 \\
NA & $a_{0}$ & 0,015086 & 0,000383 & 39,38647 & 0 \\
NA & $a_{1}$ & 1,003153 & 0,000581 & 1725,713 & 0 \\
NI & $a_{0}$ & $-0,00661$ & 0,000535 & $-12,3501$ & $5,46 \mathrm{E}-35$ \\
NI & $a_{1}$ & 0,954483 & 0,001515 & 629,965 & 0 \\
SI & $a_{0}$ & 0,002781 & 0,000277 & 10,0473 & $9,6 \mathrm{E}-24$ \\
SI & $a_{1}$ & 0,972885 & 0,000771 & 1262,482 & 0 \\
SP & $a_{0}$ & 0,010037 & 0,000637 & 15,76755 & $6,64 \mathrm{E}-56$ \\
SP & $a_{1}$ & 0,964292 & 0,001336 & 722,0428 & 0 \\
WP & $a_{0}$ & 0,009184 & 0,000327 & 28,10043 & $1,9 \mathrm{E}-173$ \\
WP & $a_{1}$ & 0,988436 & 0,000547 & 1805,75 & 0 \\
\hline
\end{tabular}

Table A5. Longitude displacement model performance

\begin{tabular}{lrrllll}
\hline BASIN & r.squared & adj.rsquared & sigma & logLik & \multicolumn{1}{l}{ AIC } & \multicolumn{1}{l}{ BIC } \\
\hline EP & 0,938957 & 0,938956 & 0,099135 & 50974,43 & -101943 & -101916 \\
NA & 0,962725 & 0,962724 & 0,130055 & 71591,53 & -143177 & -143148 \\
NI & 0,885566 & 0,885564 & 0,102887 & 43858,24 & $-87710,5$ & $-87683,9$ \\
SI & 0,912809 & 0,912808 & 0,104326 & 128085,6 & -256165 & -256135 \\
SP & 0,891146 & 0,891144 & 0,154137 & 28721,5 & -57437 & $-57409,8$ \\
WP & 0,93579 & 0,93579 & 0,151794 & 104328,6 & -208651 & -208620 \\
\hline
\end{tabular}


Table A6. SST max pressure drop (MPD) fitted per basin

\begin{tabular}{llrrrl}
\hline Basin & term & \multicolumn{1}{l}{ estimate } & \multicolumn{1}{l}{ std.error } & \multicolumn{1}{l}{ statistic } & \multicolumn{1}{l}{.value } \\
\hline EP & A & $-105,864403$ & 59,0082553 & $-1,79406089$ & 0,07557578 \\
EP & B & 216,33658 & 56,8372515 & 3,80624633 & 0,00023344 \\
EP & C & 0,05628076 & 0,02115271 & 2,66068791 & 0,00897579 \\
NA & A & 28,7995804 & 3,35824242 & 8,57578959 & $3,3364 \mathrm{E}-15$ \\
NA & B & 84,695705 & 3,1701454 & 26,7166626 & $1,9979 \mathrm{E}-66$ \\
NA & C & 0,13622543 & 0,01609221 & 8,46530416 & $6,6597 \mathrm{E}-15$ \\
NI & A & 236,806446 & 416,635007 & 0,56837866 & $\mathbf{0 , 5 7 3 1 2 1 6 3}$ \\
NI & B & $-146,277206$ & 412,517817 & $-0,35459609$ & $\mathbf{0 , 7 2 4 8 5 2 5 8}$ \\
NI & C & $-0,07639704$ & 0,18282089 & $-0,41787918$ & $\mathbf{0 , 6 7 8 3 8 7 4 3}$ \\
SI & A & $-62,2851897$ & 33,105493 & $-1,88141556$ & 0,06210122 \\
SI & B & 182,175869 & 31,0263184 & 5,87165601 & $3,2659 \mathrm{E}-08$ \\
SI & C & 0,06336423 & 0,01752514 & 3,61561831 & 0,00042407 \\
SP & A & 35,7695739 & 1,57571107 & 22,7005919 & $1,3966 \mathrm{E}-61$ \\
SP & B & 86,6674565 & 3,31645684 & 26,1325447 & $5,1892 \mathrm{E}-72$ \\
SP & C & 0,1891261 & 0,01602943 & 11,7986812 & $1,2761 \mathrm{E}-25$ \\
WP & A & 24,5280132 & 1,84123458 & 13,3215037 & $6,0587 \mathrm{E}-29$ \\
WP & B & 108,574571 & 2,13073179 & 50,9564702 & $5,533 \mathrm{E}-112$ \\
WP & C & 0,16268092 & 0,0093875 & 17,3295268 & $7,9738 \mathrm{E}-41$ \\
\hline & & & & &
\end{tabular}

Table A7. James and Mason (2005) depression dynamic parameters estimates using non-linear least square on the full sample

\begin{tabular}{|l|r|r|r|rr|}
\hline & Estimate & Std. Error & $\mathrm{t}$ value & $\operatorname{Pr}(>|t|)$ & \\
\hline$c_{0}$ & -33.691390 & 15.541681 & -2.168 & 0.0302 & $*$ \\
$c_{1}$ & -0.512631 & 0.002736 & -187.340 & $<2 \mathrm{e}-16$ & $* * *$ \\
$c_{2}$ & 2.945711 & 4.712377 & 0.625 & 0.5319 & \\
$c_{3}$ & -0.002297 & 0.001072 & -2.142 & 0.0322 & $*$ \\
\hline
\end{tabular}

Signif. codes: 0 '***' 0.001 '**' 0.01 '*' 0.05 '? 0.1 ' ’ 1

distance to MPD is computed based on the climate data extracted along track in ERA-5, and the depression dynamics are derived from IBTrACS 
https://doi.org/10.5194/gmd-2021-384

Preprint. Discussion started: 2 December 2021

(c) Author(s) 2021. CC BY 4.0 License.

Table A8. Parameter fitted per basin of the Kaplan and DeMaria (1995) simple decay function

\begin{tabular}{|c|c|c|c|c|c|}
\hline Group & Term & Estimate & std.error & Statistic & p.value \\
\hline EP & $\alpha$ & 0,051575 & 0,005396 & 9,558603 & $9,92 \mathrm{E}-21$ \\
\hline EP & $\mathrm{R}$ & 0,737096 & 0,022258 & 33,11628 & $2,3 \mathrm{E}-160$ \\
\hline EP & $V_{b}$ & 12,05551 & 0,866538 & 13,91227 & $3,58 \mathrm{E}-40$ \\
\hline EP & $d_{1}$ & $-0,01645$ & 0,003426 & $-4,80294$ & $1,82 \mathrm{E}-06$ \\
\hline EP & $\widetilde{c_{1}}$ & 0,002492 & 0,000489 & 5,095317 & $4,2 \mathrm{E}-07$ \\
\hline EP & $t_{0, L}$ & 65,53595 & 7,833239 & 8,366392 & $2,11 \mathrm{E}-16$ \\
\hline NA & $\alpha$ & 0,032612 & 0,000923 & 35,33544 & $6,7 \mathrm{E}-260$ \\
\hline NA & $\mathrm{R}$ & 0,728091 & 0,005702 & 127,6861 & 0 \\
\hline NA & $V_{b}$ & 15,79335 & 0,615452 & 25,6614 & $2,6 \mathrm{E}-141$ \\
\hline NA & $d_{1}$ & $-0,00337$ & 0,000134 & $-25,0693$ & 4E-135 \\
\hline NA & $\widetilde{c_{1}}$ & 0,000647 & $2,33 \mathrm{E}-05$ & 27,76838 & $2,2 \mathrm{E}-164$ \\
\hline NA & $t_{0, L}$ & 167,0024 & 3,309993 & 50,454 & 0 \\
\hline NI & $\alpha$ & 0,046658 & 0,000803 & 58,09956 & 0 \\
\hline NI & $\mathrm{R}$ & 0,898662 & 0,00395 & 227,5273 & 0 \\
\hline NI & $V_{b}$ & 15,97531 & 0,16293 & 98,05023 & 0 \\
\hline NI & $d_{1}$ & $-0,00017$ & $2,54 \mathrm{E}-05$ & $-6,632$ & $3,4 \mathrm{E}-11$ \\
\hline NI & $\widetilde{c_{1}}$ & $4,93 \mathrm{E}-05$ & $3,61 \mathrm{E}-06$ & 13,65886 & $2,85 \mathrm{E}-42$ \\
\hline NI & $t_{0, L}$ & 216,7443 & 6,990241 & 31,0067 & 7E-206 \\
\hline SI & $\alpha$ & 0,034892 & 0,001216 & 28,68297 & 2,2E-171 \\
\hline SI & $\mathrm{R}$ & 0,77276 & 0,008626 & 89,58485 & 0 \\
\hline SI & $V_{b}$ & 15,2878 & 0,343397 & 44,51936 & 0 \\
\hline SI & $d_{1}$ & $-0,00122$ & $8,86 \mathrm{E}-05$ & $-13,7116$ & $2,94 \mathrm{E}-42$ \\
\hline SI & $\widetilde{c_{1}}$ & 0,000212 & $1,52 \mathrm{E}-05$ & 13,93422 & $1,45 \mathrm{E}-43$ \\
\hline SI & $t_{0, L}$ & 190,6242 & 6,176902 & 30,86081 & $1,8 \mathrm{E}-196$ \\
\hline SP & $\alpha$ & 0,042668 & 0,002506 & 17,0265 & $1,37 \mathrm{E}-61$ \\
\hline SP & $\mathrm{R}$ & 0,878713 & 0,015066 & 58,32569 & 0 \\
\hline SP & $V_{b}$ & 14,56667 & 0,401468 & 36,28355 & $7 \mathrm{E}-232$ \\
\hline SP & $d_{1}$ & $-0,0013$ & 0,00015 & $-8,65747$ & $8,5 \mathrm{E}-18$ \\
\hline SP & $\widetilde{c_{1}}$ & 0,000237 & $2,67 \mathrm{E}-05$ & 8,862234 & $1,46 \mathrm{E}-18$ \\
\hline SP & $t_{0, L}$ & 184,8033 & 9,862341 & 18,73828 & $2,08 \mathrm{E}-73$ \\
\hline WP & $\alpha$ & 0,048641 & 0,001269 & 38,32268 & $4 \mathrm{E}-301$ \\
\hline WP & $\mathrm{R}$ & 0,803915 & 0,006452 & 124,603 & 0 \\
\hline WP & $V_{b}$ & 11,4317 & 0,358271 & 31,90795 & $1,9 \mathrm{E}-213$ \\
\hline WP & $d_{1}$ & $-0,00852$ & 0,000331 & $-25,746$ & 7,4E-142 \\
\hline WP & $\widetilde{c_{1}}$ & 0,001635 & $5,9 \mathrm{E}-05$ & 27,71353 & $2,7 \mathrm{E}-163$ \\
\hline WP & $t_{0, L}$ & 92,98964 & 1,767613 & 52,60746 & 0 \\
\hline
\end{tabular}

